\title{
Chronic pancreatitis, pseudotumors and other tumor-like lesions
}

\author{
Günter Klöppel \\ Department of Pathology, University of Kiel, Kiel, Schleswig-Holstein, Germany
}

\begin{abstract}
Chronic pancreatitis is a fibroinflammatory disease of the pancreas. Etiologically, most cases are related to alcohol abuse and smoking. Recently, gene mutations have been identified as the cause of hereditary pancreatitis. Other chronic pancreatitis types that were defined in recent years are autoimmune pancreatitis (lymphoplasmacytic sclerosing pancreatitis) and paraduodenal pancreatitis ('groove pancreatitis', 'cystic dystrophy of heterotopic pancreas'). This review describes and discusses the main histological findings, the pathogenesis and the clinical features of the various types of chronic pancreatitis. In addition, pseudotumors and other tumor-like lesions are briefly mentioned.
\end{abstract}

Modern Pathology (2007) 20, S113-S131. doi:10.1038/modpathol.3800690

Keywords: chronic pancreatitis; types; etiology; histopathology; pathogenesis

Chronic pancreatitis is characterized by fibroinflammatory changes to the pancreatic tissue. It may develop in association with alcohol abuse, smoking, gene mutations, autoimmune syndromes, metabolic disturbances, environmental conditions and anatomical abnormalities. ${ }^{1-3}$ Chronic pancreatitis is a rare disease that affects from 7 to 10 persons/ 100000 per year. $^{4}$ The largest numbers of patients are found in industrialized countries and approximately $80 \%$ of them are alcoholics. Alcoholic pancreatitis and most of the other etiological forms present in adulthood. Exceptions are hereditary pancreatitis, which may already occur in childhood, and tropical pancreatitis, which often affects adolescents. ${ }^{5}$

The pathology of chronic pancreatitis was formerly considered to be uniform, but currently it is more and more seen as varying according to the etiology of the disease. The rather vague term chronic sclerosing pancreatitis should and can be replaced by etiologically derived terms, such as alcoholic chronic pancreatitis, hereditary pancreatitis, autoimmune pancreatitis, ${ }^{6-11}$ paraduodenal pancreatitis ('groove pancreatitis', 'cystic dystrophy of heterotopic pancreas') ${ }^{12-14}$ and obstructive chronic pancreatitis. Some morphological features, such as the composition of the inflammatory infiltrate and the fibrosis pattern, may be a clue to a certain

Correspondence: Professor G Klöppel, MD, Department of Pathology, University of Kiel, Michaelisstr. 11, Kiel, SchleswigHolstein 24105, Germany.

E-mail: gkloeppel@path.uni-kiel.de

Received 18 July 2006; accepted 26 July 2006 etiology. ${ }^{15}$ For instance, the development of fibrosis, whether it is more inter (peri) lobular or intralobular, depends very much on the site of the initial injury in the pancreas and this is strongly related to the acting etiological factor. Apart from these more general mechanisms, chronic pancreatitis is very much an individualized disease that, although driven by the same etiology, may progress rapidly in one patient while developing slowly and being clinically insignificant in another patient.

For the pathogenesis it is important to note that alcoholic chronic pancreatitis, hereditary pancreatitis and duodenal wall pancreatitis evolve from recurrent acute pancreatitis. ${ }^{15-17}$ Further, a diagnosis of chronic pancreatitis must take into account that the pancreas of patients over 60 may show fibrosis that is not associated with the clinical symptoms of chronic pancreatitis but seems to be the result of hyperplastic changes in the epithelium of secondary ducts. ${ }^{15}$

\section{Classification}

Since 1963 several classifications of chronic pancreatitis have been introduced. ${ }^{18,19}$ These classifications were mainly concerned with the distinction between acute and chronic pancreatitis. Moreover, they focused primarily on alcohol-induced chronic pancreatitis and only marginally considered the nonalcoholic types. Finally, none of the classifications correlated the etiology with morphological, functional and clinical features. Hence, there is still a need for a classification that includes all currently 
Table 1 Etiologic classification of chronic pancreatitis and pancreatic fibrosis

\author{
Chronic pancreatitis \\ Alcoholic \\ Nonalcoholic \\ Hereditary \\ Metabolic (hypercalcemia, hyperlipidemia) \\ Autoimmune \\ Idiopathic \\ Tropical \\ Other forms \\ Chronic pancreatitis associated with anatomic abnormalities ${ }^{\mathrm{a}}$ \\ Obstructive chronic pancreatitis ${ }^{\mathrm{a}}$ \\ Periampullary duodenal wall cysts \\ Pancreas divisum \\ Post-traumatic pancreatic scars
}

Pancreatic fibrosis not associated with symptoms of chronic pancreatitis

Pancreatic fibrosis in the elderly

Cystic fibrosis ${ }^{\mathrm{b}}$

Pancreatic fibrosis in long-term insulin dependent diabetes mellitus

Hemochromatosis

${ }^{\mathrm{a}}$ Usually only associated with pancreatic insufficiency.

${ }^{\mathrm{b}}$ Associated with pancreatic insufficiency.

available criteria for the characterization of the various types of chronic pancreatitis. Table 1 presents a classification proposal based on the etiology of the disease.

\section{Alcoholic chronic pancreatitis}

\section{Clinical Features}

The patients are usually young to middle-aged men (25-50 years), who develop the disease after approximately 10 years of alcohol abuse. The younger the patients are when they begin their abuse, the shorter the time required for chronic pancreatitis to develop seems to be. However, of the total number of heavy drinkers, only $10 \%$ suffer from chronic pancreatitis. At the early stage of alcoholic chronic pancreatitis, patients experience relapsing episodes of acute pancreatitis, particularly with severe recurrent pain. In its advanced stage, alcoholic chronic pancreatitis is characterized by pain, steatorrhea and diabetes. In addition, patients with this disease have an increased risk of developing a pancreatic carcinoma later in life, particularly if they have a hereditary form of chronic pancreatitis that starts very early in life..$^{4,20}$

\section{Pathology}

In the early stages of alcoholic chronic pancreatitis, the gland shows unevenly distributed fibrosis. The involved parts of the gland appear indurated and may be enlarged, showing coarse lobulation and/or nodular scarring on the cut surface. Only the ducts

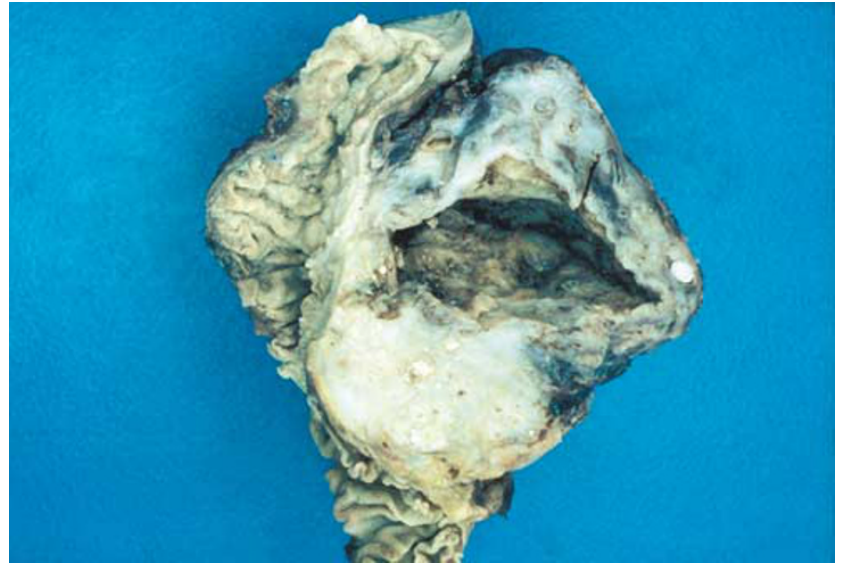

Figure 1 Alcoholic chronic pancreatitis: pancreatic head resection specimen from a patient with chronic pancreatitis of 5 years' duration showing scarring of the parenchyma, calculi and an extrapancreatic pseudocyst.

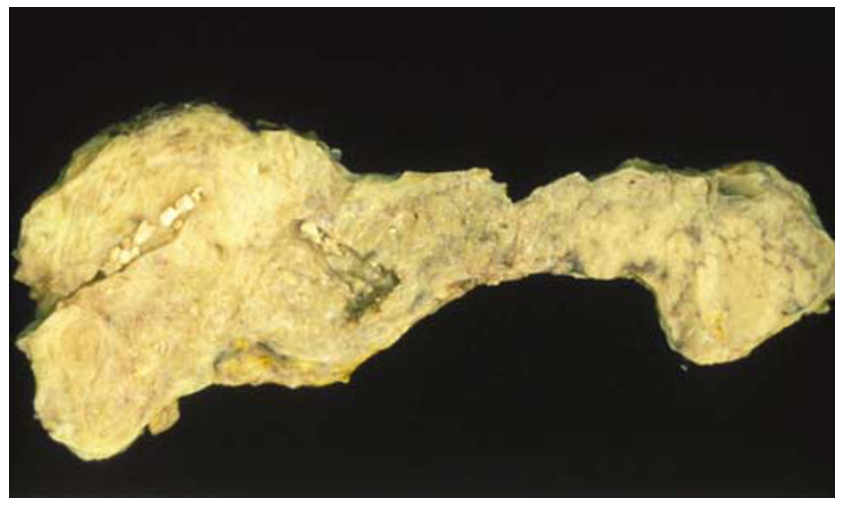

Figure 2 Alcoholic chronic pancreatitis: advanced stage characterized by calculi in the pancreatic duct and diffuse but patchy fibrosis of the parenchyma.

that are embedded in fibrotic tissue show irregularities and occasionally may contain calculi (calcified protein plugs) (Figure 1). In $30-50 \%$ of the cases there may be pseudocysts, which are usually extrapancreatic ${ }^{16,21-23}$ and commonly occur in the region around the body and tail of the pancreas. In addition, there are foci of recent necrosis in the vicinity of scars ${ }^{24}$ and pseudocysts.

In advanced chronic pancreatitis, the pancreas has a firm consistency and usually shows an irregular contour without the normal lobulation. ${ }^{17,25}$ The fibrosis may diffusely affect the entire gland, but occasionally it is still unevenly distributed, leaving the lobular pattern of the organ preserved in some areas (Figure 2). The severity of the duct changes depends on the extent of the surrounding fibrosis. Thus, the main duct may be only focally obstructed and/or dilated or diffusely involved with irregular dilatation and distortion. Usually $(80 \%)$ it contains calculi. The calculi, which consist of calcium carbonate, vary in size from less than $1 \mathrm{~mm}$ to more than $1 \mathrm{~cm}$ in diameter. They may be 


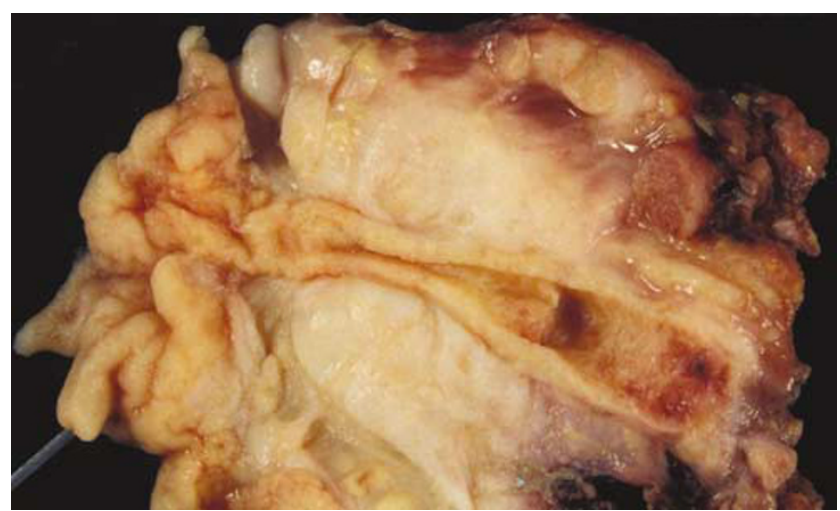

Figure 3 Alcoholic chronic pancreatitis: pancreatic head resection specimen showing intense scarring of the parenchyma causing a tapering stenosis of the common bile duct.

impacted in the ducts and therefore difficult to remove. In some cases, they may disappear during the course of the disease. ${ }^{23,26}$ Fibrosis in the pancreas head may cause a tapering stenosis of the common bile duct (Figure 3). Thick-walled pseudocysts, usually attached to the pancreas, are present in one quarter to one half of the cases. ${ }^{21}$ They vary in size $(3-10 \mathrm{~cm}$ in diameter) and are filled with necrotic material and/or turbid fluid rich in enzymes. The pseudocysts may be connected with the duct system. Occasionally, they may erode the major portal veins causing thrombosis, bleeding and, rarely, disseminated fat necrosis with subcutaneous nodular panniculitis, polyarthritis and necrotic bone marrow lesions. ${ }^{23}$

Histological examination of the early stages of the disease reveals interlobular (perilobular) cell-rich fibrosis ${ }^{16,27,28}$ (Table 2, Figure 4). The involved intralobular ducts are distorted and may contain eosinophilic secretions, the so-called protein plugs. In addition, the epithelium may display metaplastic or hyperplastic changes. Moderate numbers of lymphocytes, plasma cells and macrophages are present, either in local accumulations or scattered diffusely throughout the fibrous tissue. In the perilobular tissue, there may be foci of resolving fat necrosis (Figure 5) with large numbers of vacuolated macrophages (foam cells) in the immediate vicinity and cell-rich fibrosis in the surrounding area. The necrotic foci are often in the vicinity of large pseudocysts, which lie outside the pancreatic parenchyma.

In advanced chronic pancreatitis, fibrosis affects most of the parenchyma, but still to varying degrees. ${ }^{16,27,29}$ While in some areas there is only perilobular fibrosis (Figure 6a), others show diffuse intralobular fibrosis with sparse lymphocytic infiltrates. Perilobular fibrosis causes duct distortions and dilatations with occasional formation of a retention cyst. The lumens of these interlobular ducts are often filled with protein plugs and calculi (Figure 6b). The duct epithelium is either atrophic or completely replaced by polymorphocellular in-
Table 2 Diagnostic criteria for an etiological classification of chronic pancreatitis (CP)

\begin{tabular}{|c|c|c|c|c|c|}
\hline & $A C P$ & $H P$ & $A I P$ & $P P$ & $O C P$ \\
\hline \multicolumn{6}{|l|}{ Necrosis } \\
\hline Pseudocyst & +++ & + & - & + & - \\
\hline Autodigestive necrosis & + & $(+)$ & - & ++ & - \\
\hline \multicolumn{6}{|l|}{ Fibrosis } \\
\hline Diffuse & + & + & +++ & - & +++ \\
\hline Focal & ++ & ++ & + & +++ & - \\
\hline Perilobular & +++ & +++ & +++ & ++ & ++ \\
\hline Intralobular & + & + & +++ & + & ++ \\
\hline Periductal & - & +++ & +++ & + & + \\
\hline \multicolumn{6}{|l|}{ Duct lumen } \\
\hline Dilated & +++ & +++ & - & +++ & +++ \\
\hline Obstructed & - & - & +++ & + & - \\
\hline Irregular & +++ & + & - & +++ & - \\
\hline \multicolumn{6}{|l|}{ Duct contents } \\
\hline Precipitate & + & ++ & - & +++ & - \\
\hline Calculus & ++ & + & - & + & - \\
\hline Granulocytes & $(+)$ & + & ++ & + & - \\
\hline \multicolumn{6}{|l|}{ Duct epithelium } \\
\hline Hyperplastic & $(+)$ & $(+)$ & - & - & ++ \\
\hline Destroyed & $(+)$ & + & ++ & +++ & - \\
\hline Regenerated & $(+)$ & $(+)$ & - & - & - \\
\hline
\end{tabular}

ACP, alcoholic chronic pancreatitis; HP, hereditary pancreatitis; AIP, autoimmune pancreatitis; PP, paraduodenal pancreatitis; OCP, obstructive chronic pancreatitis.

+++ denotes frequent/extensive, + denotes rare/few.

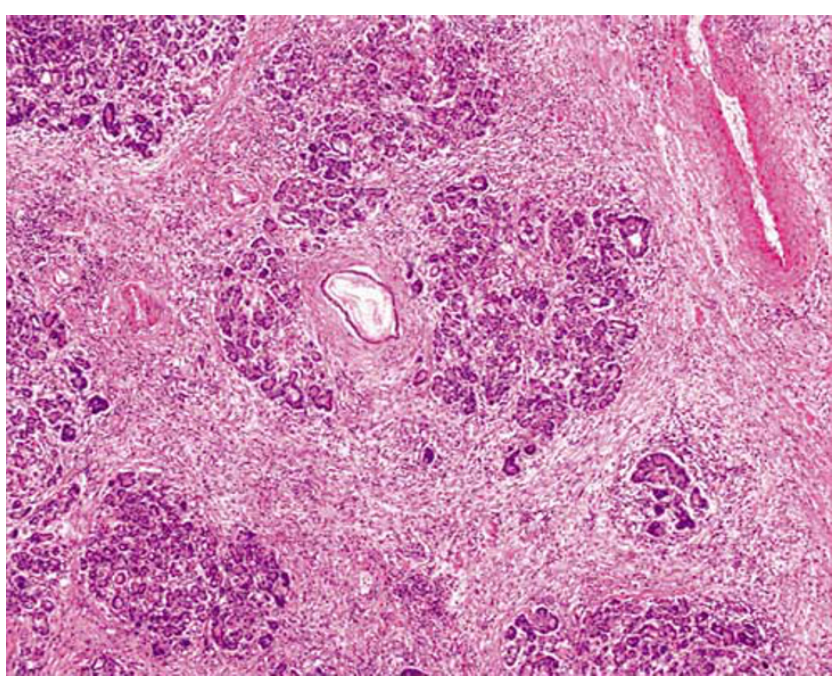

Figure 4 Alcoholic chronic pancreatitis, early stage: acinar lobule with interlobular (perilobular) cell-rich fibrosis.

flammatory tissue. In areas with intralobular fibrosis, the elements that remain are islets, thick-walled blood vessels, prominent nerves and remnants of acinar cells, which may be atrophic, undergo apoptosis, or form the so-called tubular complexes. ${ }^{30}$ The nerves have been found to be damaged by the inflammatory process. ${ }^{31}$ The islets may form large ('adenomatoid') aggregates (Figure 7), which 


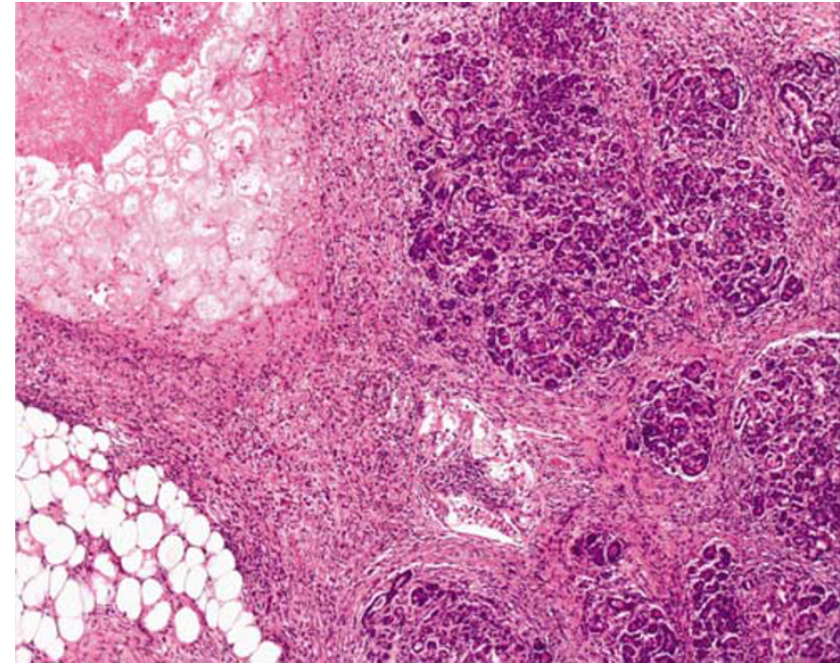

Figure 5 Alcoholic chronic pancreatitis, early stage: pancreatic parenchyma with resolving fat necrosis in the perilobular tissue (upper left corner). Macrophages and cell-rich fibrosis in the surrounding area.
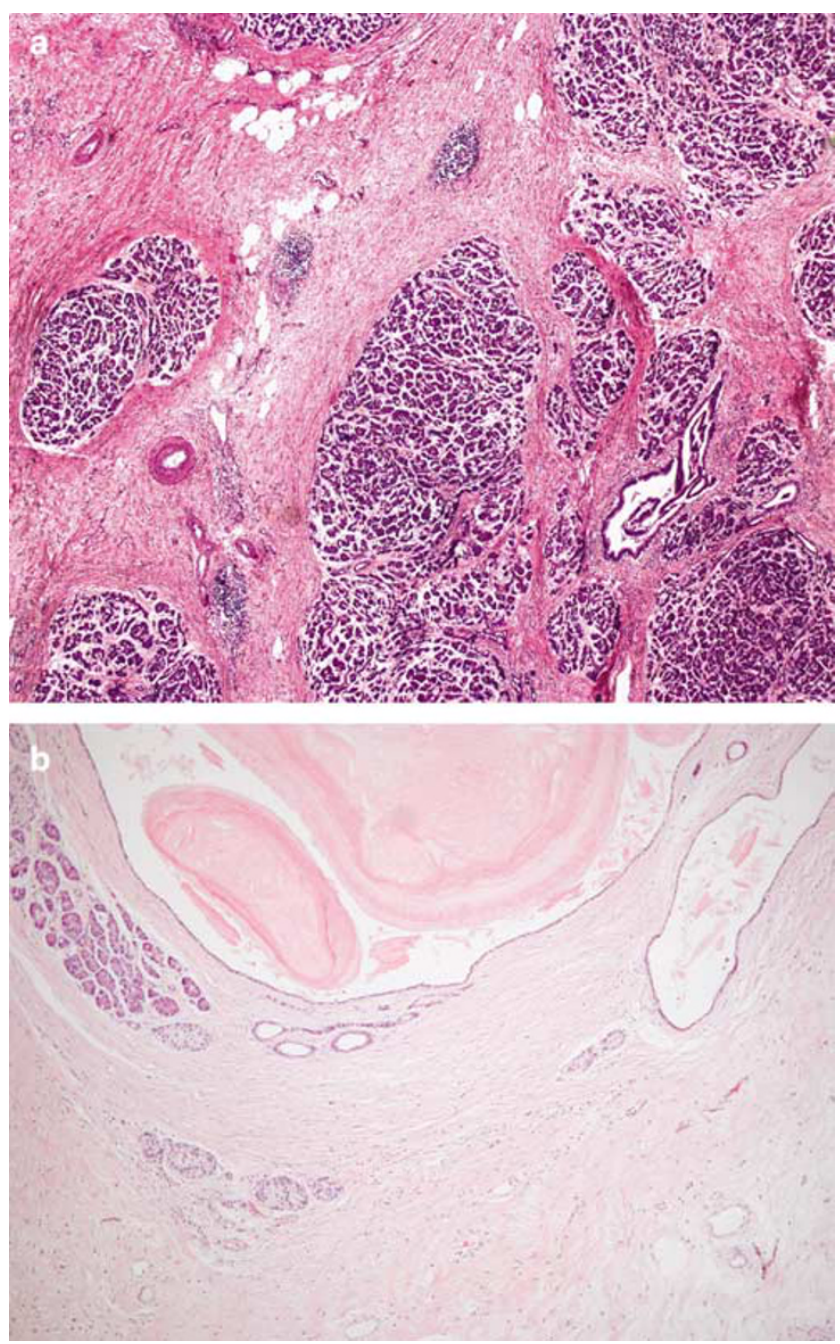

Figure 6 Alcoholic chronic pancreatitis, advanced stage: intensive perilobular (a) and intralobular fibrosis. Distorted ducts with protein plugs (b).

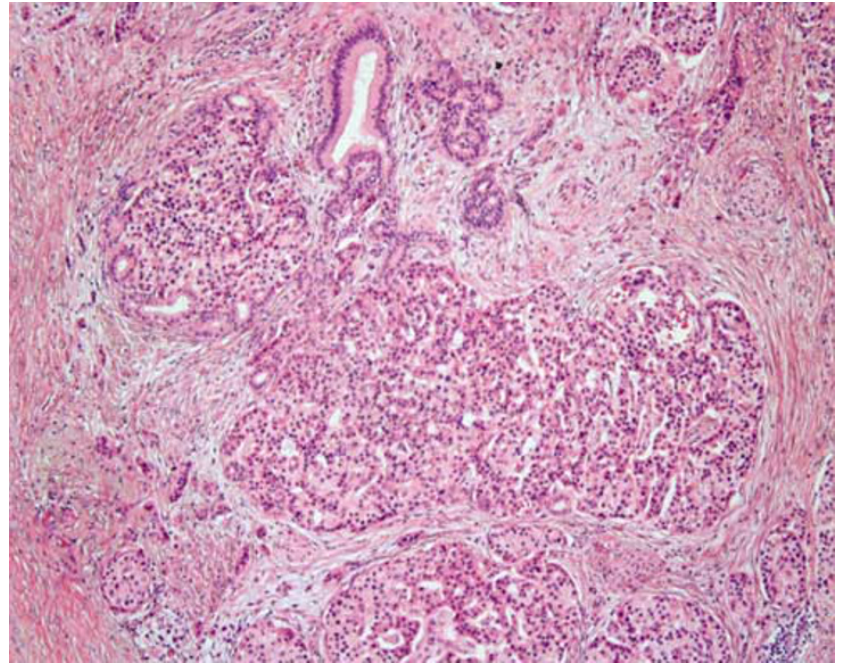

Figure 7 Alcoholic chronic pancreatitis, advanced stage: large islet aggregates in the fibrotic tissue.

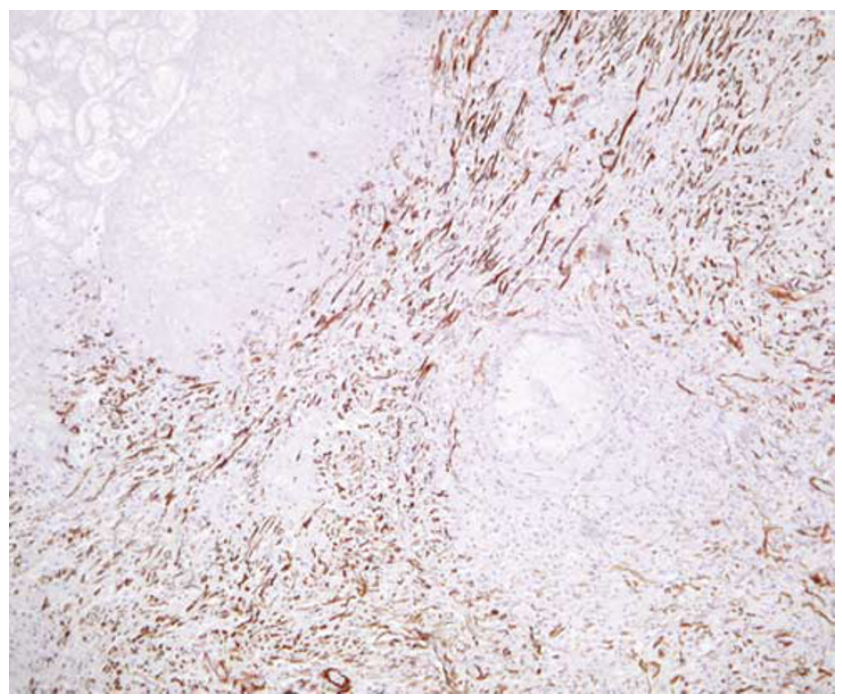

Figure 8 Alcoholic chronic pancreatitis, early stage: two areas of recent necrosis surrounded by numerous myofibroblasts, also called pancreatic stellate cells, identified by immunostaining for smooth muscle actin.

are sometimes in close contact with ductules that show islet cell neoformation. ${ }^{32}$ The number of beta cells in these islets was found to be slightly reduced. ${ }^{32}$

Immunohistological studies revealed that the duct epithelium commonly expresses HLA-DR and cytokines such as transforming growth factors alpha and beta (TGF $\alpha, \mathrm{TGF} \beta 1)$ and fibroblast growth factor $(\mathrm{FGF})^{33-38}$ TGF $\beta 1$ and platelet derived growth factor (PDGF) were also found in fibroblasts, macrophages and/or platelets. ${ }^{28,39,40}$ Myofibroblasts, which were recently named pancreatic stellate cells, are identified by their positivity for smooth muscle actin and desmin $^{15}$ (Figure 8). ${ }^{28,41-43}$ The lymphocytic infiltrate consists largely of $\mathrm{T}$ lymphocytes. ${ }^{33,34}$ The 
remaining acinar cells stain brightly for pancreatic enzymes and pancreatic stone protein. ${ }^{44,45}$ The nerves that appear enlarged express particularly calcitonin-gene related peptide and substance $\mathrm{P}^{46}$ Both the endothelial cells and endocrine beta and alpha cells show strong endothelin-1 expression in chronic pancreatitis. ${ }^{47}$

\section{Symptoms, Function and Complications}

Persistent stenosis of the bile duct develops in approximately $10 \%$ of the cases, ${ }^{48}$ duodenal stenosis in about $3 \%{ }^{29}$ These complications are either due to intensive scarring or to the development of a pseudocyst in the head of the pancreas.

Pseudocysts are found in $30-50 \%$ of patients with chronic pancreatitis. ${ }^{16,21}$ They are usually thickwalled, the wall consists of granulation and fibrous tissue and lacks an epithelial lining. ${ }^{21}$ Identical features are observed in pseudocysts associated with acute pancreatitis. Pseudocysts are usually connected with the duct system and therefore rich in pancreatic enzymes. They may expand and exert pressure on the surrounding organs. Further complications are fistulas into the pleura, leakage of pancreatic juice into the peritoneal cavity (pancreatic ascites), or hemorrhages from eroded vessels into the cysts and the pancreatic duct system. Some pancreatic duct stents used for the treatment of chronic pancreatitis have been found to cause changes in the duct system that may aggravate the chronic pancreatitis they are treating. ${ }^{49,50}$

With increasing fibrosis of the pancreas, the patients develop exocrine and endocrine insufficiency. ${ }^{16}$ Exocrine insufficiency results in maldigestion, which usually becomes obvious after $80-90 \%$ of the parenchyma has been replaced by fibrosis. The incidence of diabetes increases with the duration and severity of chronic pancreatitis. ${ }^{16}$

The question whether chronic pancreatitis involves an increased risk for the development of pancreatic ductal carcinoma has been a controversial issue for years. It now appears that patients with chronic pancreatitis, particularly if they have the hereditary form,$^{51}$ have a higher risk of developing pancreatic carcinoma than the normal population. $^{20,52}$ It is interesting that K-ras mutations, which are very common in ductal adenocarcinoma, may also occur in the hyperplastic duct epithelium of the pancreas in patients with chronic pancreatitis, particularly with a duration of more than 3 years. ${ }^{53}$

\section{Pathogenesis}

In all westernized countries, alcohol is the most common cause of chronic pancreatitis. ${ }^{54,55}$ In addition, smoking seems to be an independent etiological factor. ${ }^{56}$ The reason why only $10 \%$ of alcoholics develop chronic pancreatitis is unclear. ${ }^{57}$ Presumably, there is an additional (genetic?) factor in the development of alcoholic chronic pancreatitis that makes certain patients more susceptible to the disease than others. Recently, mutations of the cystic fibrosis transmembrane regulator gene (CFTR) have been implicated in the pathogenesis of chronic pancreatitis and it has been suggested that the functional consequences of these mutations (ie impaired flow of secretion) could predispose their bearer to the development of chronic pancreatitis. ${ }^{58}$ Whether the alcoholic who remains free of chronic pancreatitis may develop some particular kind of diffuse fibrosis of the pancreas ${ }^{59}$ distinct from that which can be seen in elderly patients without any known risk factors for chronic pancreatitis has yet to be established.

Several theories have been put forth to explain the pathogenesis of alcoholic chronic pancreatitis. The most popular hypothesis is that of Sarles et al, ${ }^{60}$ who suggested that chronic ethanol consumption increases the protein concentration in the pancreatic juice with subsequent precipitation of plug-forming secretions in the ducts, which later calcify. More recently, Sarles' group ${ }^{61-63}$ identified a protein in pancreatic juice that prevented $\mathrm{CaCO}_{3}$ precipitation and was therefore called lithostatin (formerly pancreatic stone protein). It is thought that abnormal secretion of lithostatin due to either an acquired or an inherited defect in its biosynthesis contributes to the calcification of protein plugs in the pancreatic ducts. The formation of stones leads in turn to duct obstruction and ulceration of duct epithelium, two mechanisms that cause acinar atrophy and fibrosis upstream of the obstruction as well as periductular inflammation. Although this hypothesis is attractive, it has been criticized for several reasons. First, the findings concerning altered lithostatin biosynthesis and function in chronic pancreatitis have not been universally confirmed. ${ }^{64-66}$ Second, the hypothesis only recognizes chronic pancreatitis as an alcohol-induced disease and neglects the fact that acute pancreatitis may also be caused by alcohol. ${ }^{67-70}$ Third, alcoholic acute and chronic pancreatitis have many features in common, such as clinical symptoms and the presence of pseudocysts. Fourth, in alcoholic acute pancreatitis, no pre-existent changes due to chronic pancreatitis have been found, whereas the pancreas of patients with chronic pancreatitis may show signs of acute pancreatitis, such as autodigestive tissue necrosis. ${ }^{21,25}$ Fifth, in its early stages chronic pancreatitis lacks calcifications. ${ }^{16}$

In recent years, the plug hypothesis has been challenged by the necrosis-fibrosis sequence concept. $^{24,71}$ This theory postulates that alcoholic chronic pancreatitis is initiated by relapsing severe acute pancreatitis. ${ }^{16,72}$ The resorption of large areas of fat necrosis and hemorrhagic necrosis, which are the main events in severe acute (necrotizing) pancreatitis ${ }^{17}$ induce fibrosis, possibly through the action of growth factors such as TGF $\alpha$ and TGF $\beta^{37}$ (Figure 9). ${ }^{35}$ The fibrosis develops primarily in the 
S118

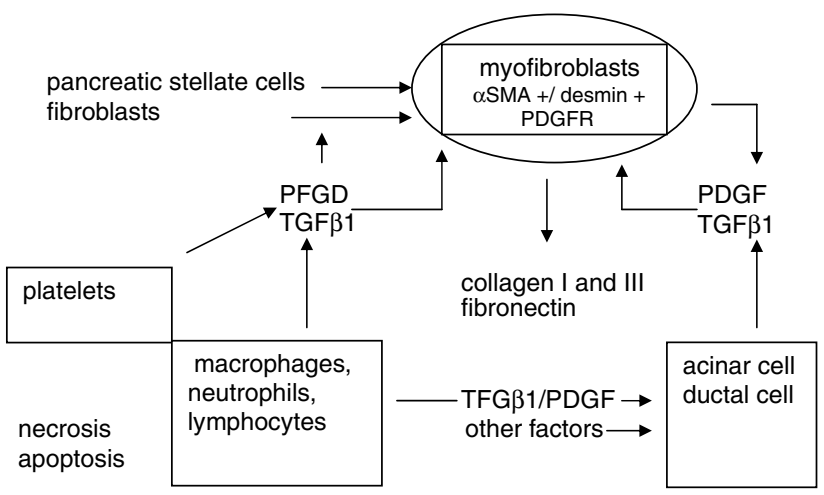

Figure 9 Mechanisms of fibrogenesis in the pancreas. PSC, pancreatic stellate cell; TGF $\beta 1$, tumor growth factor $\beta 1$; PDGR, platelet-derived growth factor; SMA, smooth-muscle actin; ECM, extracellular matrix (adapted from Klöppel et $a l^{15}$ ).

perilobular space, where fat necrosis and most of the hemorrhagic necrosis occur. ${ }^{15,17}$ Perilobular fibrosis in turn affects the structure of the interlobular ducts, gradually creating duct dilatations and strictures ${ }^{73}$ (Figure 10). In these altered ducts, the flow of secretions is most likely impaired, a situation that may trigger the spontaneous precipitation of proteins with subsequent calcification. In addition, the impaired and eventually interrupted flow of pancreatic secretions leads to fibrotic replacement of the acinar cells upstream from the occluded duct and finally results in intralobular fibrosis.

Although the necrosis-fibrosis sequence nicely explains the perilobular fibrosis pattern, the patchy distribution of fibrosis and the late occurrence of calcifications in the pancreas of patients with alcoholic chronic pancreatitis, certain questions still need to be answered. First, it is difficult to reconcile the fact that the necrosis-fibrosis sequence also holds true for the primary painless chronic pancreatitis that may be observed in $5-10 \%$ of alcoholics ${ }^{74-76}$ Second, biliary acute pancreatitis, which may occasionally be as severe as alcoholic pancreatitis, virtually never progresses to chronic pancreatitis.

A third hypothesis, called the 'toxic-metabolic hypothesis' was put forth by Bordalo et $a l^{77}$ and Noronha et $a l^{78}$ This hypothesis postulates that chronic alcohol consumption induces progressive acinar lipid deposition with acinar atrophy and intrapancreatic fibrosis by exerting direct toxic and metabolic effects on the acinar cells. Because the described pancreatic changes, particularly the fatty degeneration of acinar cells, have not been confirmed by others, the significance of this concept for the pathogenesis of alcoholic chronic pancreatitis seems to be minor.

The fourth hypothesis, the 'oxidative stress hypothesis', ${ }^{79}$ postulates that oxidative stress in pancreatic acinar cells induced by excess free radicals causes a blockade of the intracellular pathway, fusion of lysosomal and zymogenic compartments, and membrane lipid oxidation. These events then lead to an inflammatory response. The hypothesis focuses on possible functional disturbances underlying acinar failure, but fails to explain the particular fibro-inflammatory process that characterizes chronic pancreatitis.

\section{Hereditary pancreatitis}

\section{Clinical Findings}

Hereditary pancreatitis usually starts already in childhood or adolescence. Clinically, it resembles alcoholic pancreatitis. It is very rare, compared with alcoholic chronic pancreatitis, and accounts for no more than $1-2 \%$ of all patients. ${ }^{5}$

\section{Pathogenesis}

It has recently been shown that the genetic alterations in hereditary chronic pancreatitis involve the cationic trypsinogen gene (PRSS1) or the serine protease inhibitor Kazal type 1 (SPINK1) gene. ${ }^{80-82}$ The third gene with mutations associated with chronic pancreatitis is the cystic fibrosis gene, CFTR. Mutations in the first two genes, PRSS1 and SPINK1, seem to trigger the autoactivation of trypsinogen in the pancreas, which in turn results in the early inappropriate activation of the other pancreatic enzymes with subsequent autodigestive necrosis and inflammation. The most important trypsinogen gene mutations, R122H and N21I, are gain of function mutations and have a disease penetrance of $80 \% .^{58}$ SPINK1 mutations are loss of function mutations and may result in elevated trypsin levels within the pancreas. So far the role of the CFTR mutations in the pathogenesis of chronic pancreatitis is unclear.

\section{Pathology}

We do not yet know where in the pancreas the premature activation of trypsin takes place. It may occur either already in the acinar cells or only in the duct system. We studied pancreatic resection specimens from six patients with hereditary chronic pancreatitis (unpublished observation) and found advanced chronic pancreatitis with massively dilated ducts containing protein plugs and calculi (Figure 11). The fibrosis showed a periductal and interlobular pattern (Table 2). In one case, there was ductal necrosis in some of the medium-sized interlobular ducts that destroyed the duct epithelium and led to an intense chronic inflammatory reaction in the periductal area (Figure 12). This finding suggests that the autodigestive process in hereditary chronic pancreatitis may occur in the duct lumen, resulting initially in necrosis of the duct-lining cells and subsequently affecting the surrounding interstitial tissue. If we hypothesize that the relapsing autodigestive necrosis occurs particularly in the large ducts, it may gradually 

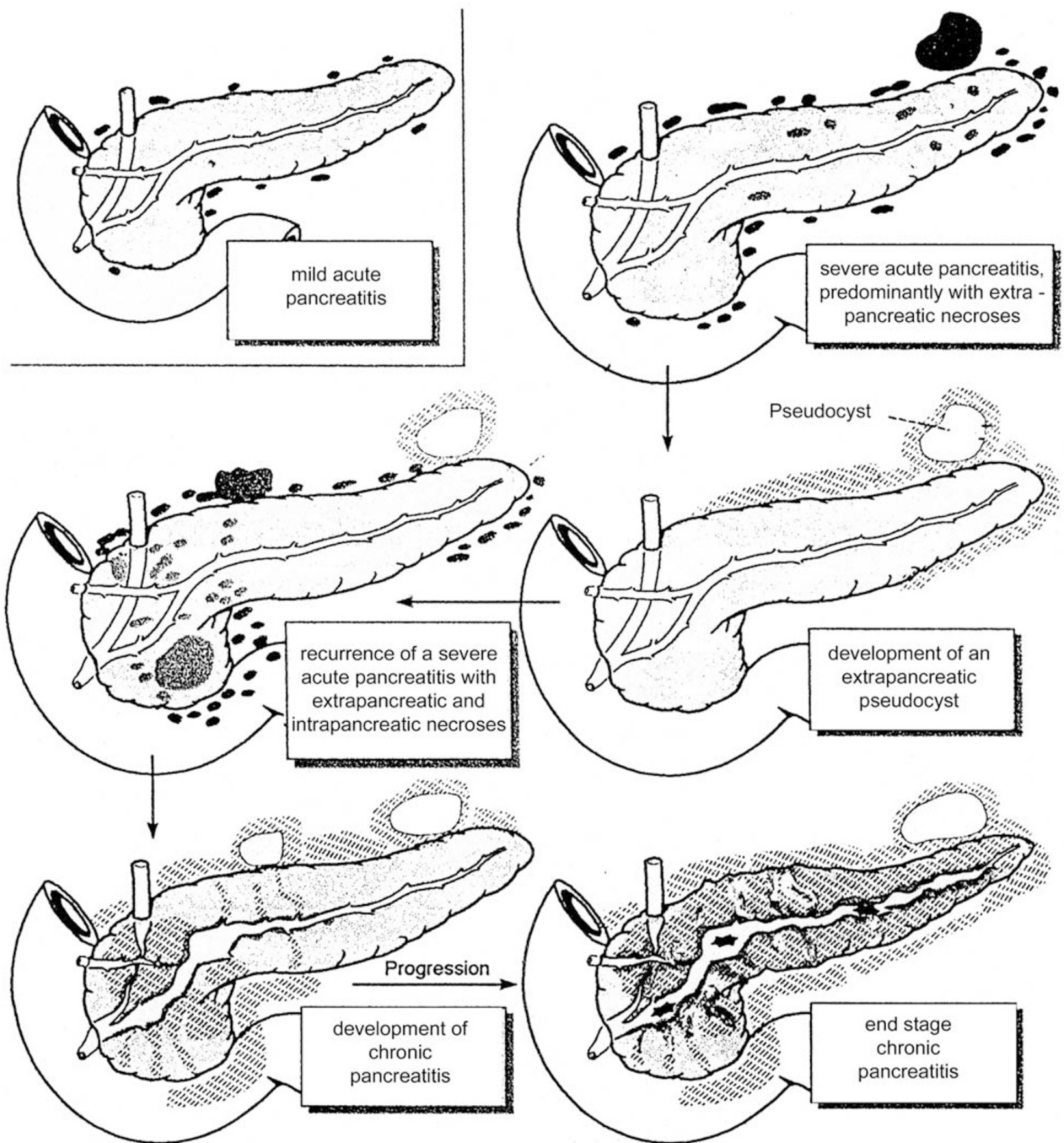

necrosis

㺟敂 fibrosis

$\rightarrow$ calculus

Figure 10 Natural history of alcoholic pancreatitis. Mild acute pancreatitis is characterized by spotty peripancreatic fat necrosis, which is resolved without inducing significant fibrosis. Severe acute pancreatitis with large confluent areas of peripancreatic necrosis, but little intrapancreatic involvement, leads to an extrapancreatic pseudocyst. Relapse of severe acute pancreatitis with extensive extra- and intrapancreatic foci of necrosis induces perilobular fibrosis and duct distortions. In addition, there may be extrapancreatic pseudocysts. Early stage chronic pancreatitis evolve into end-stage chronic pancreatitis with severe duct changes, diffuse but still patchy fibrosis and calculi (adapted from Klöppel ${ }^{73}$ ).

induce scarring of the surrounding interstitial tissue with subsequent dilatation of the involved duct segments. In addition, there may also be autodiges- tive necrotic events in the interlobular areas next to ducts that initiate and promote interlobular fibrosis. Large areas of necrosis may be transformed into a 
S120

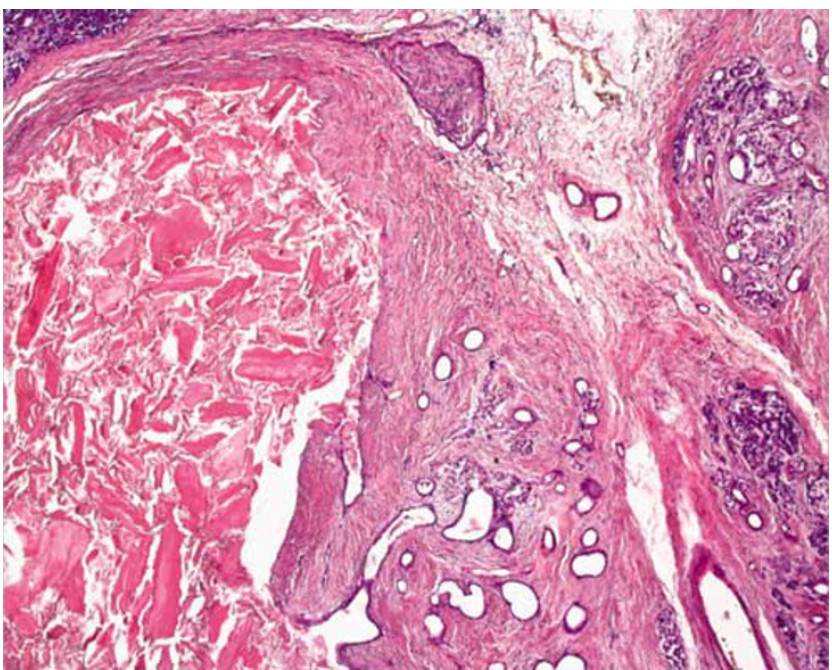

Figure 11 Hereditary chronic pancreatitis: massively dilated duct surrounded by fibrotic tissue that extends into the perilobular regions.

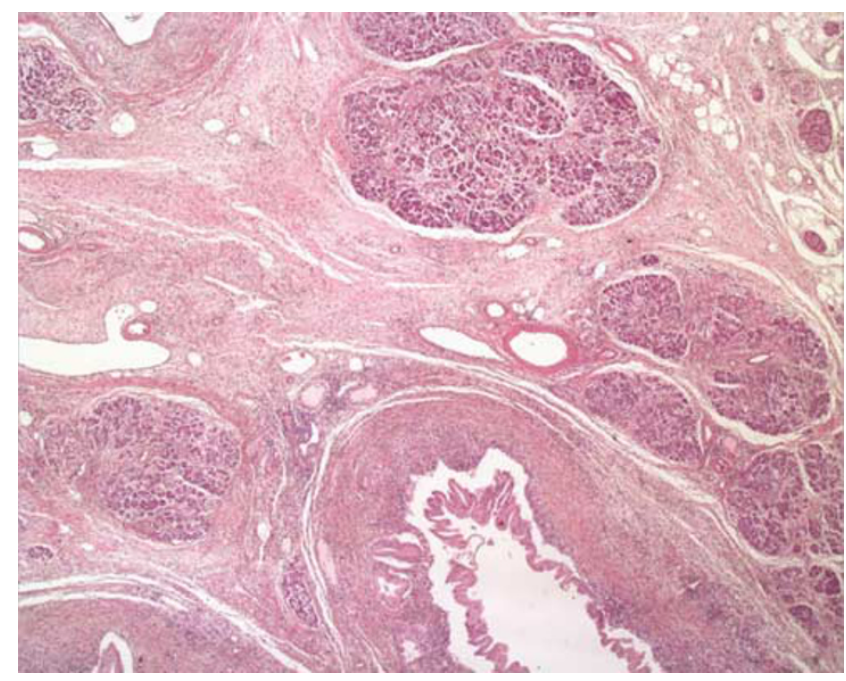

Figure 12 Hereditary chronic pancreatitis: interlobular duct (bottom) with periductal inflammation and fibrosis. Interlobular fibrosis.

pseudocyst. ${ }^{83}$ The calculi found in the dilated ducts are probably a result of the obstructed flow of pancreatic secretions, which promotes the precipitation of calcium from the pancreatic juice.

\section{Autoimmune pancreatitis}

In recent years, autoimmune pancreatitis has been established as a special type of chronic pancreatitis. The first reports describing such pancreatitis date back more than 50 years. Ball et $a l^{84}$ described patients with pancreatitis in conjunction with ulcerative colitis. In 1961, Sarles et al ${ }^{85}$ reported a case of sclerosing pancreatitis with hypergamma- globulinemia. The term autoimmune pancreatitis was coined in the 1990s. ${ }^{86}$ Meanwhile, a number of reports on individual cases or small series of cases using other terms, such as lymphoplasmacytic sclerosing pancreatitis with cholangitis, ${ }^{7}$ nonalcoholic duct destructive chronic pancreatitis ${ }^{6}$ and chronic sclerosing pancreatitis, have been published. ${ }^{87}$

\section{Clinical Findings}

Most patients suffering from autoimmune pancreatitis are 40-60 years old (mean: 56) ${ }^{6,10,11,88}$ It appears that the patients who have a more pronounced neutrophilic inflammatory cell infiltrate ('granulocytic epithelial lesions') ${ }^{11}$ are usually in their mid40s. The gender ratio also varies with the histologic pattern; the younger group with neutrophilic inflammation contains equal numbers of men and women, whereas the older group lacking neutrophils is predominantly male (ratio 3:1).

Clinical symptoms include abdominal pain, anorexia and jaundice. Jaundice is caused by direct involvement of the bile duct by the fibroinflammatory process and occurs in about $75-80 \%$ of the patients. In approximately $20 \%$ of the patients, there are associated diseases that are thought to be of autoimmune origin: Sjögren's syndrome, idiopathic retroperitoneal fibrosis, lymphocytic thyroiditis and ulcerative colitis. Some of these conditions appear to be more common in one of the two clinical subgroups of patients. Sjögren's syndrome is more often reported in older male patients without neutrophilic inflammation, whereas chronic inflammatory bowel disease often occurs in the younger patients who have neutrophilic inflammatory infiltrates in the pancreas. ${ }^{9,11}$

Patients with autoimmune pancreatitis may have autoantibodies such as antinuclear, antilactoferrin, antismooth muscle and anticarbonic anhydrase II antibodies. ${ }^{89,90}$ More recently it has been observed that IgG4 levels are commonly elevated in patients with autoimmune pancreatitis. ${ }^{91}$ Elevated IgG4 levels have been used to correctly classify patients with pancreatic masses. ${ }^{92}$ Imaging of the pancreas by CT or MRI often discloses a diffusely or segmentally enlarged pancreas with obliteration or stenosis of the main pancreatic duct. Bile duct strictures also occur when the disease affects the head of the gland. Ultrasonography may reveal a diffusely swollen hypoechoic pancreas, which has been referred to as 'sausage-like.'

\section{Pathology}

Information about the pathology of autoimmune pancreatitis is available from case reports and several small series that were recently published..$^{6,7,9,10,87,88,93,94}$ Our knowledge is based on a 


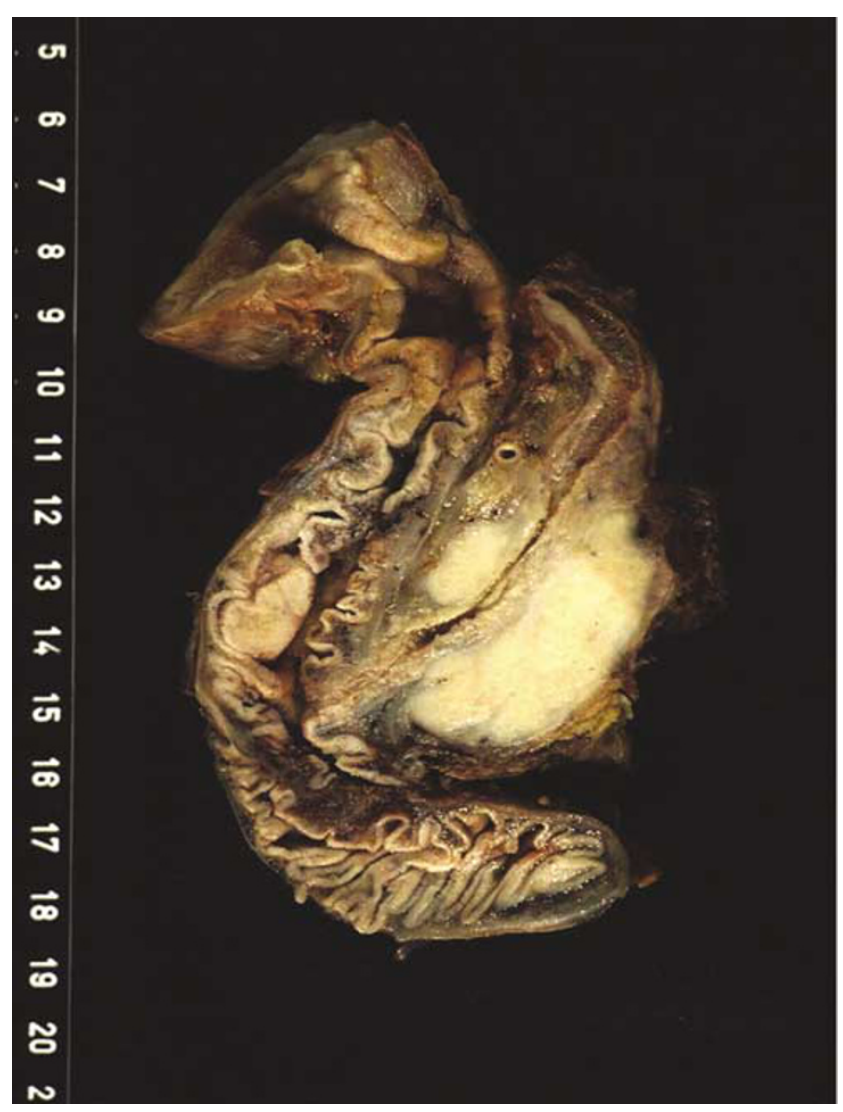

Figure 13 Autoimmune pancreatitis: pancreatic head resection specimen showing replacement of the pancreatic parenchyma by fibrous tissue and stenosis of the distal bile duct.

series of 63 cases that were accumulated in Germany, Belgium and Italy. ${ }^{11}$

The gross appearance of autoimmune pancreatitis mimics pancreatic ductal carcinoma because the inflammatory process, like the carcinoma, commonly focuses on the head of the pancreas and leads to a gray to yellowish-white induration of the affected tissue with loss of its normal lobular structure (Figure 13). The involved portions may be enlarged. These changes cause obstruction of the main pancreatic duct and usually also of the distal bile duct, including the papilla. ${ }^{95}$ In a minority of cases, the inflammatory process is concentrated in the body or tail of the pancreas. Diffuse involvement of the pancreas may also be seen, but so far it is not known how frequently and to what extent the entire pancreas is affected in autoimmune pancreatitis. In contrast to other types of chronic pancreatitis, such as alcoholic chronic pancreatitis, hereditary pancreatitis and tropical pancreatitis, there are no pseudocysts. Calculi (ie intraductal calcifications) are usually absent, but if they occur, they seem to occur late in the course of the disease. ${ }^{96}$

The hallmark of the histological changes in the pancreas in autoimmune pancreatitis is an intense inflammatory cell infiltration around medium-sized and large interlobular ducts. ${ }^{6,7,9,11}$ Smaller ducts

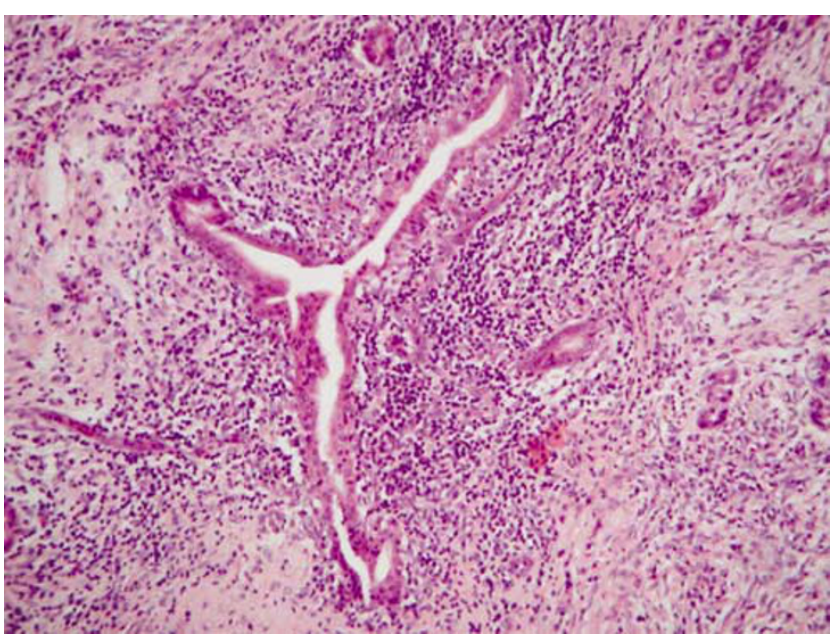

Figure 14 Autoimmune pancreatitis: medium-sized duct showing typical periductal lymphoplasmacytic inflammation and narrowing of the lumen.

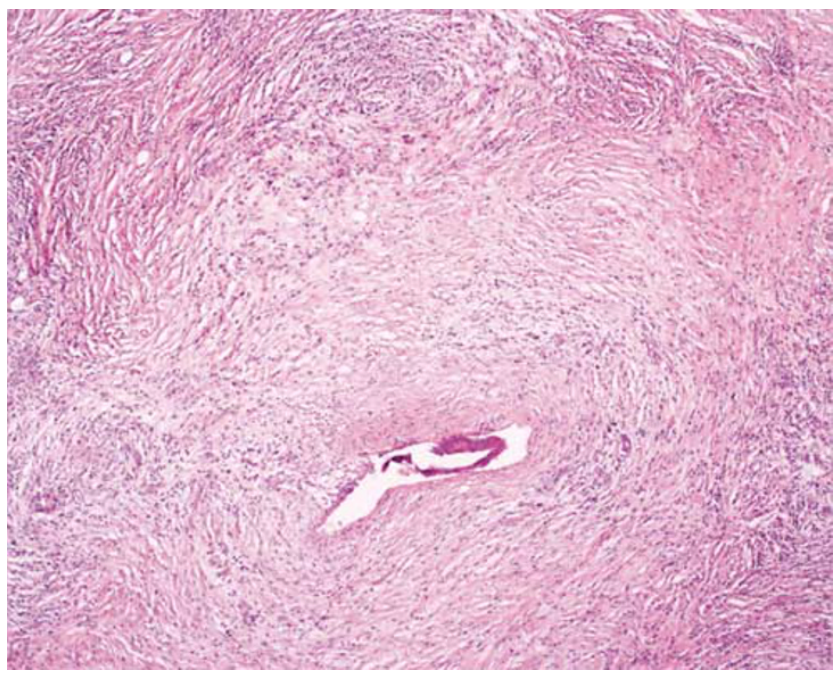

Figure 15 Autoimmune pancreatitis: medium-sized duct showing intensive periductal fibrosis.

may also be involved, but only in advanced cases. The inflammatory infiltrate consists mainly of lymphocytes and plasma cells (Figure 14), but also contains some macrophages and occasionally also neutrophilic and eosinophilic granulocytes. ${ }^{97} \mathrm{Im}$ munocytochemical typing of the lymphocytes reveals that most of them are CD8 and CD4 positive T lymphocytes with fewer B lymphocytes. The infiltrate completely encompasses the ducts and may narrow their lumen by infolding of the epithelium, often giving the lumen a star-like structure. In later stages, the duct wall is thickened by periductal fibrosis (Figure 15).

In a number of cases, the chronic changes in the pancreas are overlain by 'granulocytic-epithelial' lesions of the ducts (Figure 16). This acute inflammatory component of autoimmune pancreatitis is 


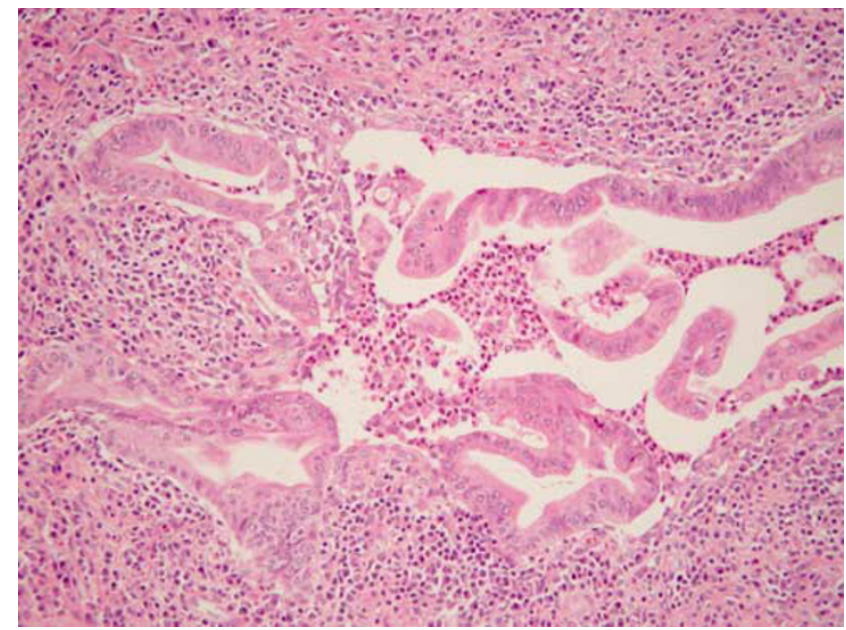

Figure 16 Autoimmune pancreatitis: pancreatic duct showing a granulocytic epithelial lesion, that is, destruction of the epithelium by invading granulocytes.

characterized by focal detachment, disruption and destruction of the duct epithelium due to invading neutrophilic and occasionally also eosinophilic granulocytes, which may also cluster immediately beneath the duct epithelium. Sometimes the granulocytic infiltration extends into the small intralobular ducts and acini. Although these acute duct changes may be severe, total duct destruction leaving scars that replace the ducts seems to be a rare event.

The extension and severity of the chronic and acute changes in autoimmune pancreatitis vary from case to case and even from one area to another within a single pancreas. In some cases, the inflammatory process occupies only a relatively small part of the pancreas and alternates abruptly with areas in which only minimal inflammation is found or the pancreatic tissue is even normal. If the tissue is only slightly affected, the inflammation focuses almost entirely on the ducts, while in severely affected pancreases the inflammatory process involves the acinar parenchyma, in addition to the ducts, and leads to diffuse sclerosis ${ }^{15}$ (Figure 17) that may contain scattered $B$ cell rich small lymphoid follicles. The acinar cells are then more or less replaced by inflammatory cells and fibrosis and the lobular architecture of the pancreas is almost lost. If the fibrotic changes occupy large areas that show myofibroblasts in a storiform arrangement, they may mimic the features of an inflammatory pseudotumor..$^{98,99}$

In addition to the duct changes and the sclerotic process, there are vascular changes. Most frequent is vasculitis affecting the small veins (Figure 18). Less common is obliterative arteritis.

If the inflammatory process affects the head of the gland (as in approximately $80 \%$ of the cases), it usually also involves the distal common bile duct, where it leads to a marked thickening of the bile

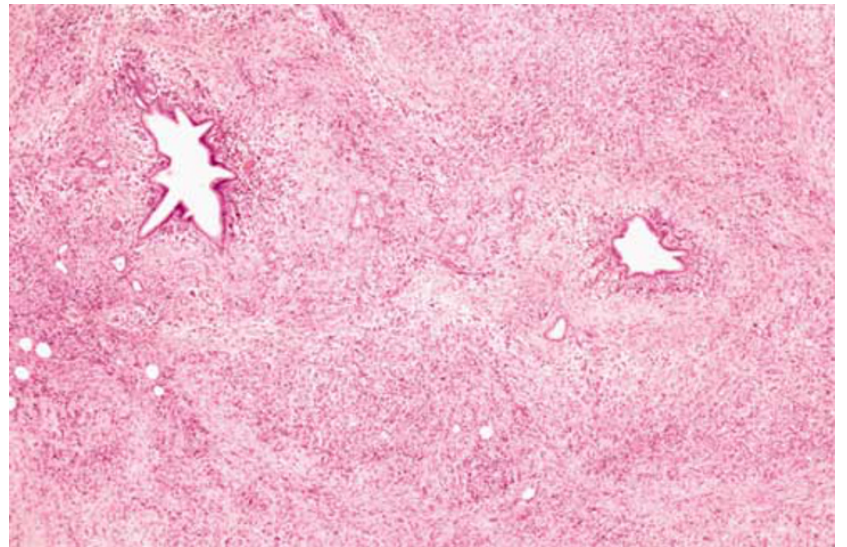

Figure 17 Autoimmune pancreatitis: lymphoplasmacytic infiltration and fibrosis replaces almost all acinar tissue and small ducts.

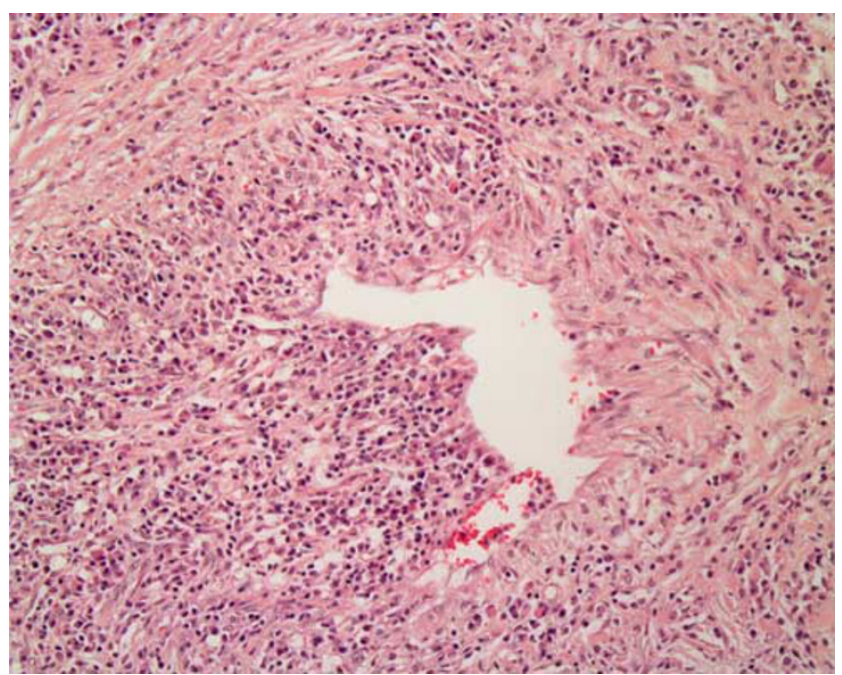

Figure 18 Autoimmune pancreatitis: venulitis.

duct wall due to a diffuse lymphoplasmacytic infiltration combined with fibrosis. In some cases, the inflammation also extends to the hepatic ducts of the liver hilus and the gall bladder wall. ${ }^{100}$ The inflammatory process is usually well demarcated from the surrounding fatty tissue. The peripancreatic and peribiliary lymph nodes are enlarged and show follicular hyperplasia.

\section{Biopsy}

Recent studies suggest that biopsy can play a role in establishing the diagnosis of autoimmune pancreatitis. ${ }^{11,101}$ Thus, if a core biopsy specimen from the pancreas contains a duct with dense periductal lymphocytic inflammation, a vein with obliterative venulitis and/or a granulocytic epithelial lesion (Figure 19), the diagnosis can be suggested. Staining for IgG4 positive plasma cells and the demonstration of an increased number ( $>20$ cells per HPF) are 


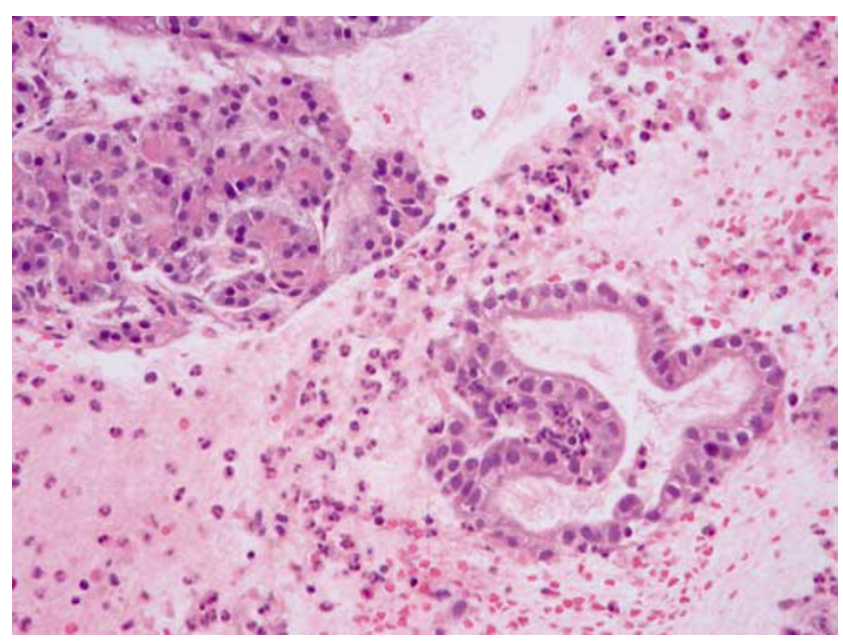

Figure 19 Autoimmune pancreatitis: core biopsy specimen showing a granulocytic epithelial lesion.

further indications pointing to a diagnosis of autoimmune pancreatitis.

\section{Relationship to Inflammatory Pseudotumor and Primary Sclerosing Cholangitis}

There are a number of reports on inflammatory (myofibroblastic) pseudotumors occurring in the head of the pancreas that involved the pancreatic duct as well as the distal common bile duct, ${ }^{102}$ some associated with retroperitoneal fibrosis. ${ }^{103-105}$ Judging from the descriptions and illustrations of these cases, these changes appear to be compatible with those seen in autoimmune pancreatitis. ${ }^{99}$ As the clinical features of the reported inflammatory pseudotumors of the pancreas are also very similar, it is likely that these lesions may represent an advanced stage of autoimmune pancreatitis in which the fibrotic changes predominate and the disease focuses on a certain area. ${ }^{11}$ The fact that inflammatory pseudotumors showing sclerosing cholangitis have been observed in the liver hilus ${ }^{106}$ suggests that there is possibly an idiopathic pancreatobiliary inflammatory disease complex whose facets include autoimmune pancreatitis, extrahepatic sclerosing cholangitis and inflammatory pseudotumor of the pancreas and/or the common bile duct.

Inflammatory and sclerosing changes of the distal bile duct (which sometimes also involve the gallbladder) are very frequent and almost an integral part of autoimmune pancreatitis. Because of their similarity to extrahepatic primary sclerosing cholangitis, a relationship with this autoimmune liver disease has been discussed. However, the primary sclerosing cholangitis-like changes in the extrahepatic bile duct system that may be seen in autoimmune pancreatitis have so far never been found to be accompanied by intrahepatic primary sclerosing cholangitis. ${ }^{100}$ Moreover, unlike typical primary sclerosing cholangitis, they appear to respond to steroid therapy. Therefore, it is likely that autoimmune pancreatitis, even if it involves the extrahepatic bile ducts, is a different disease and distinct from primary sclerosing cholangitis.

\section{Pathogenesis}

The inflammatory duct changes seen in autoimmune pancreatitis point to potential antigens within the duct epithelium that have become targets of an immmune process. Typing of the inflammatory duct-associated cells revealed CD4 + and CD8 $+\mathrm{T}$ cells to be the most common. ${ }^{6,90}$ Increased numbers of these T cells bearing HLA-DR were also found in the peripheral blood. ${ }^{107}$ Subtyping of the CD4+ cells according to their cytokine production profiles revealed a predominance of CD4 + Th1 cells over Th2 cells in some cases, ${ }^{107}$ similar to what has been reported in Sjögren's disease ${ }^{108}$ and primary sclerosing cholangitis. ${ }^{109}$ HLA-DR antigens have also been detected on pancreatic duct cells. ${ }^{6,90}$ Finally, similar to other autoimmune diseases, autoimmune pancreatitis patients show a particular HLA haplotype, namely DRB1*0405-DQB1*0401. ${ }^{110}$ Taken together these findings strongly suggest that autoimmune mechanisms may be involved in the pathogenesis of autoimmune pancreatitis. This concept is further supported by the common association of autoimmune pancreatitis with other autoimmune diseases, notably Sjögren's syndrome, ${ }^{86}$ the frequent occurrence of various autoimmune antibodies such as antibodies against carboanhydrase II and nuclear antigens, ${ }^{107}$ the elevated IgG4 serum levels and an increase in IgG4 positive plasma cells, ${ }^{91,111,112}$ the oligoclonal pattern of T-cell receptor $\gamma$ gene rearrangements ${ }^{98}$ and the responsiveness to steroid therapy. ${ }^{113-117}$ What is unclear is how this immune process is triggered in the pancreas and why it is mostly focal and not diffuse, as might be expected from an autoimmune disease.

\section{Differential Diagnosis}

Clinically, radiographically and grossly autoimmune pancreatitis most commonly mimics pancreatic ductal carcinoma, because-like the carcinomait predominantly affects the pancreatic head and the bile duct. Histologically, however, it is not difficult to distinguish from ductal adenocarcinoma of the pancreas or other pancreatic malignancies. At the histological level, autoimmune pancreatitis has to be distinguished from alcoholic chronic pancreatitis (Table 2). Autoimmune pancreatitis almost consistently lacks the features that are common in alcoholic chronic pancreatitis: calculi, dilated and tortuous ducts, pseudocyst formation and areas of fat necrosis. Histologically, alcoholic chronic pancreatitis lacks the dense periductal lymphoplasmacytic infiltration, the obliterative venulitis, the often 
diffuse fibrosis, the granulocytic epithelial lesions and the common inflammatory involvement of the bile duct. Autoimmune pancreatitis must also be distinguished from paraduodenal pancreatitis. The latter disease generally develops in the region of the pancreas between the intrapancreatic bile duct and the duodenum proximal to the ampulla of Vater and in the region of the minor papilla. In these areas, and in particular in the duodenal wall, there is inflammation and fibrosis, often associated with cystic structures. All these features are lacking in autoimmune pancreatitis.

\section{Other types of chronic pancreatitis}

\section{Metabolic Chronic Pancreatitis}

Chronic pancreatitis may be associated with hypercalcemic syndromes such as those that may occur in primary hyperparathyroidism. ${ }^{118}$ The morphological changes are similar to those seen in alcoholic chronic pancreatitis. Fibrotic changes in the pancreatic have also been observed in patients who underwent chronic dialysis because of renal insufficiency.

\section{Tropical Chronic Pancreatitis}

This disease has also been referred to as tropical calculous pancreatitis and, if diabetes is the prevailing symptom, as fibrocalculous pancreatic diabetes. Tropical chronic pancreatitis is limited to countries in central Africa, Brazil and southern Asia, especially India, which lie close to the equator. This disease is associated with malnutrition in childhood and usually occurs in adolescents. Recently, it was found that SPINK1 mutations are associated with tropical pancreatitis and therefore seem to be involved in its etiopathogenesis. ${ }^{119}$ Morphologically, tropical pancreatitis has been compared with alcoholic chronic pancreatitis. In its late stages it shows intense inter- and partly also intralobular fibrosis and contains numerous small and larger calculi. ${ }^{120}$ Nothing is known so far about the early stages of the disease.

\section{Idiopathic Chronic Pancreatitis}

Morphologically, there are no systematic studies on this type of pancreatitis; however, calcifications seem to be less frequent than in alcoholic chronic pancreatitis. ${ }^{121}$ Idiopathic pancreatitis has two age peaks, one in young patients and the other in elderly patients. ${ }^{122}$ It used to be rather common and accounted for $10-25 \%$ of all cases of chronic pancreatitis. It can be anticipated, however, that its frequency will drop, once our understanding of the etiology of chronic pancreatitis increases. It is likely that among the patients with idiopathic pancreatitis there may be some with autoimmune pancreatitis.

\section{Chronic pancreatitis associated with anatomic abnormalities}

\section{Paraduodenal Pancreatitis}

This type of pancreatitis has been described under various names in the literature, which represent the different facets of this inflammation of the pancreas: cystic dystrophy of heterotopic pancreas, ${ }^{123}$ periampullary duodenal wall cyst, ${ }^{124}$ groove pancreatitis, ${ }^{12}$ pancreatic hamartoma of the duodenal wall ${ }^{125}$ and paraduodenal pancreatitis. ${ }^{126}$ Here, we follow the proposal of Adsay and Zamboni and use the term paraduodenal pancreatitis.

Clinically, this particular pancreatic inflammation is found predominantly in male patients (40-50 years) with a history of alcohol abuse. The main symptoms are severe upper abdominal pain, postprandial vomiting and nausea due to stenosis of the duodenum and weight loss. Jaundice develops in approximately $20 \%$ of the patients. Imaging may reveal cystic changes in the duodenal wall, calcifications in the paraduodenal pancreatic tissue, pseudocysts at the duodenal wall, a tumor in the region between the duodenum and the pancreas and irregularities in the pancreatic ducts in the head of the pancreas.

Grossly, there is either thickening and scarring of the duodenal wall, particularly in the area corresponding to the minor papilla, that extend to the adjacent pancreatic head tissue (Figure 20) and/or sieve-like cystic changes in the duodenal wall (Figure 21). The cysts contain clear fluid, but others may have more granular white material and even stones. Occasionally, some of the cysts may have a diameter of several centimeters. The fibrotic tissue that develops in the wall of the pancreas and also involves the groove between the wall and the pancreatic tissue may compress and indent the common bile duct. Microscopically, the chronic inflammatory process resides in the duodenal submucosa, the duodenal wall and the adjacent pancreatic tissue (Table 2). Typically, there are several small foci of necrosis surrounded by a dense proliferation of myoid cells, which show all the features of myofibroblasts and are positive for muscle markers (Figure 22a). This change is most prominent in the area corresponding to the submucosa of the minor papilla. Between the myoid proliferations, there may be cystic ductal elements, acinar lobules and some islets as well as nerves. Apart from cystically dilated ducts, there are often pseudocystic lesions filled with acidophilic material and lined by granulation tissue with foreign body giant cell reaction (Figure 22b). Occasionally, there are also clusters of eosinophils. A common finding associated with the inflammatory changes is Brunner's gland hyperplasia, which contributes to the thickening of the duodenal mucosa. If the inflammatory process in the duodenal wall extends to the adjacent pancreas, the cellular and fibrotic 


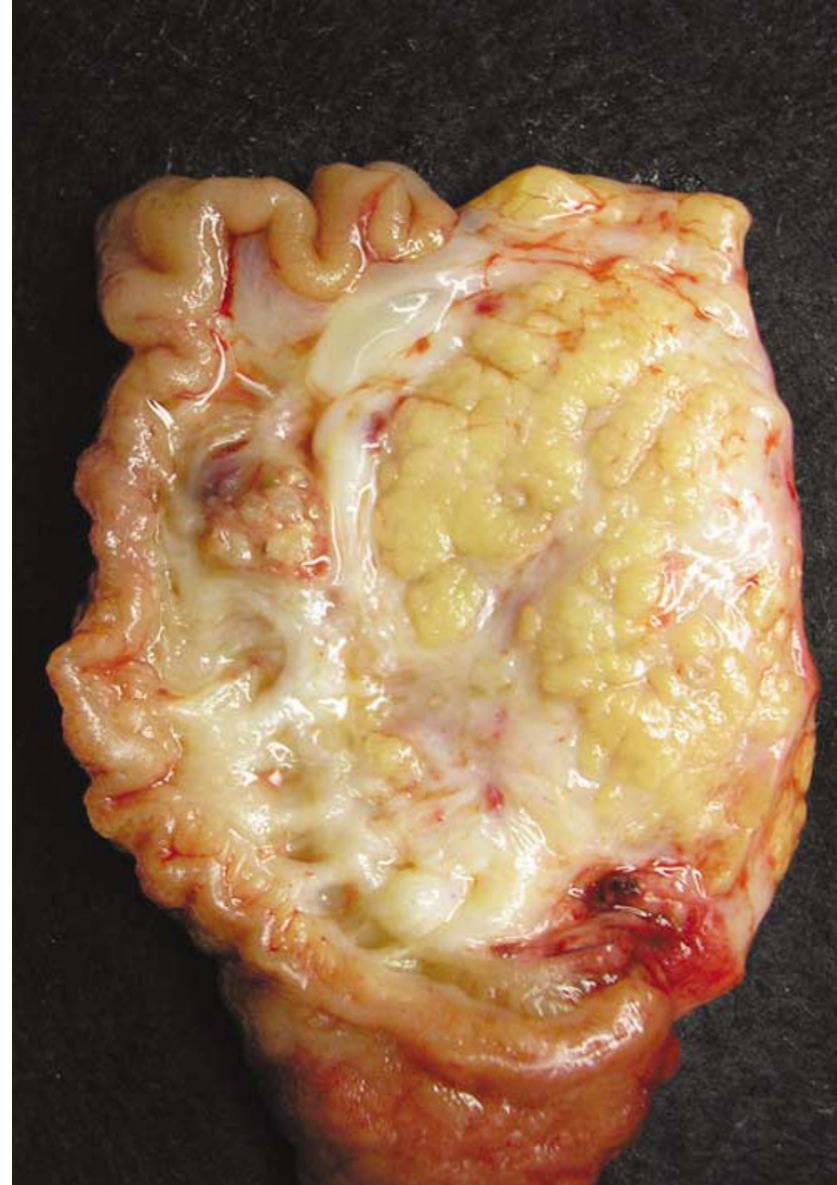

Figure 20 Paraduodenal pancreatitis: pancreatic head resection specimen showing intense scarring in the duodenal wall with extension into the adjacent pancreatic tissue.

reaction becomes less intense so that the central parts of the pancreatic head are usually not involved.

Pathogenetically, alcohol abuse appears to be a precipitating factor, since most of the patients with paraduodenal pancreatitis are alcoholics. The location of the inflammatory process suggests that there may be some anatomic variation in the region of the minor papilla that makes this appear particularly susceptible to injury by alcohol. It is therefore conceivable that the outflow is obstructed at the level of the minor papilla, as may be seen in some cases of pancreas divisum, a condition in which a fetal-type ductal drainage system persists in the adult pancreas. The fact that the duodenal wall often contains the so-called heterotopic pancreatic tissue may reflect the incomplete involution of the dorsal pancreas in this region and contribute to an obstruction of outflow in this area.

\section{Obstructive Chronic Pancreatitis}

In obstructive chronic pancreatitis, there is a focal obstruction of the main pancreatic duct or one of the

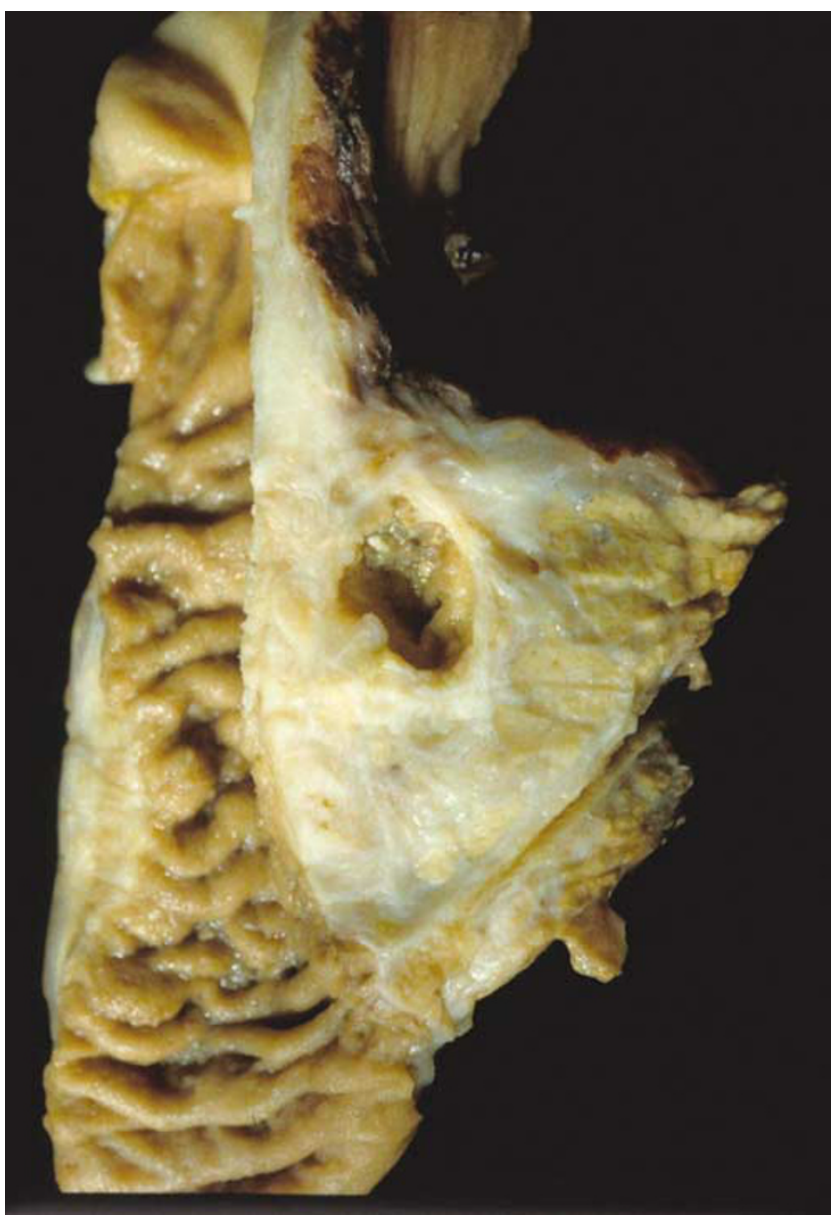

Figure 21 Paraduodenal pancreatitis: pancreatic head resection specimen showing scarring of the duodenal wall and the adjacent pancreatic. In addition, there is a cystic lesion between duodenum and pancreas.

secondary ducts that lie in the interlobular spaces, leading to ductal dilatation upstream of the stenosis and to atrophy of the acinar cells and replacement by fibrous tissue and islet aggregations. There are various possible causes for a duct obstruction, but the most important and common cause is ductal adenocarcinoma in the head of the pancreas occluding the main pancreatic duct (Figure 23). This process leads to a generalized involvement of the gland with interlobular fibrosis, which in longstanding cases is increasingly accompanied by intralobular fibrosis (Table 2). Other causes include intraductal papillary-mucinous neoplasms, some cystic and endocrine neoplasms, acquired fibrous strictures of the pancreatic ducts, ductal papillary hyperplasia narrowing the duct lumen and finally viscous mucin blocking the duct lumen.

The effects of all the listed duct obstructing mechanisms can be compared with those of duct ligation in the pancreas. ${ }^{127,128}$ In the early phase after duct ligation, the acini are transformed into small ductal (tubular) complexes. In the next step, the acinar cells disappear, probably due to apoptosis. 

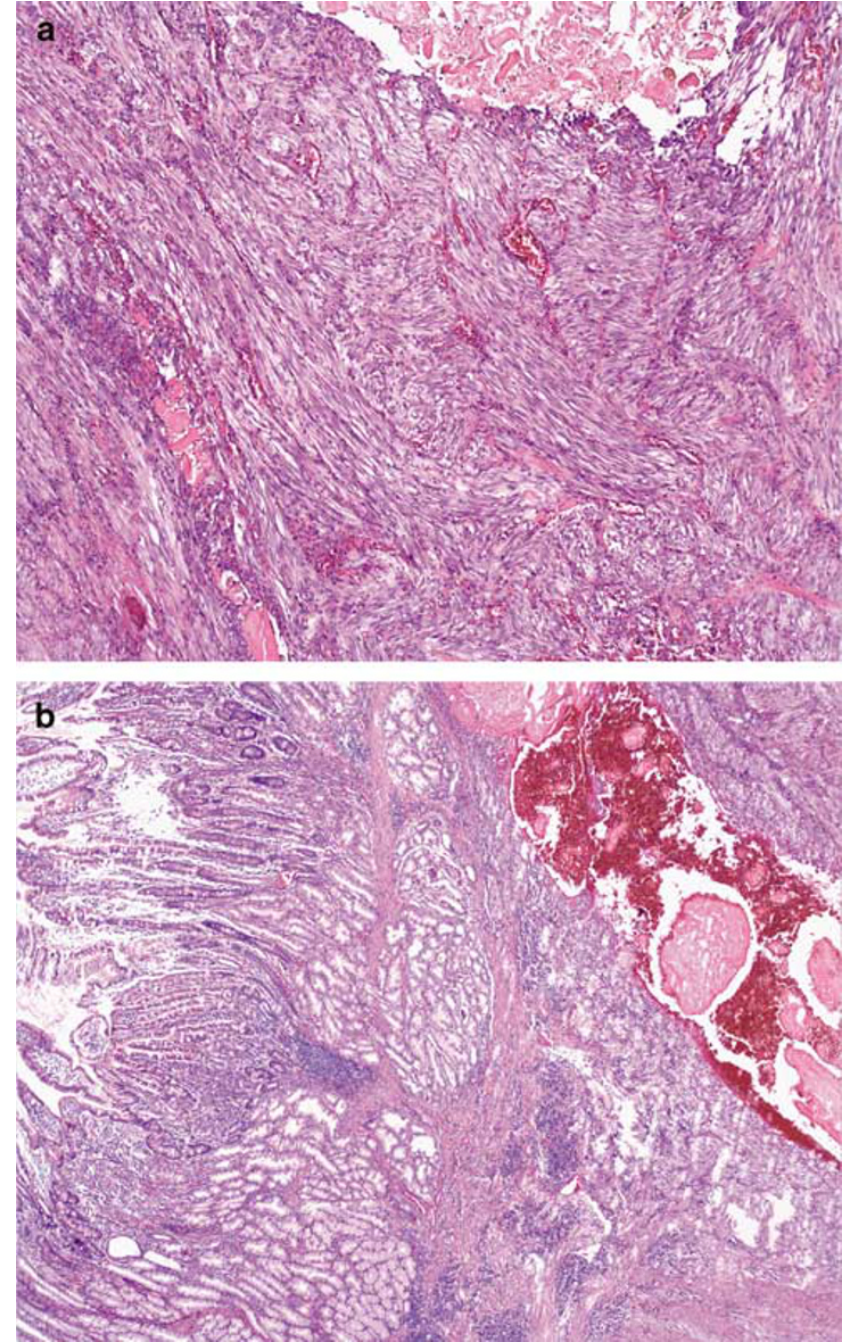

Figure 22 Paraduodenal pancreatitis: (a) focus of necrosis (top) with adjacent dense proliferation of myofibroblasts; (b) in the submucosa of the duodenum, there is a focus of necrosis surrounded by chronic inflammation.

These changes are associated with an inflammatory and fibrotic reaction involving numerous macrophages. The macrophages are the potential source of cytokines, which stimulate fibrogenesis by fibroblasts that acquire the properties of myofibroblasts. ${ }^{15}$ Because the inflammatory reaction takes place in all of the interlobular and intralobular areas of the pancreatic tissue that were once drained by the occluded duct, fibrosis develops in these regions at the same pace, producing interlobular and intralobular fibrosis in equal distribution (Figure 24).

\section{Pancreatic Fibrosis not Associated with Symptoms of Chronic Pancreatitis}

A special situation of duct fibrosis is encountered in cystic fibrosis of the pancreas and in pancreatic lobular fibrosis, which is frequently observed in

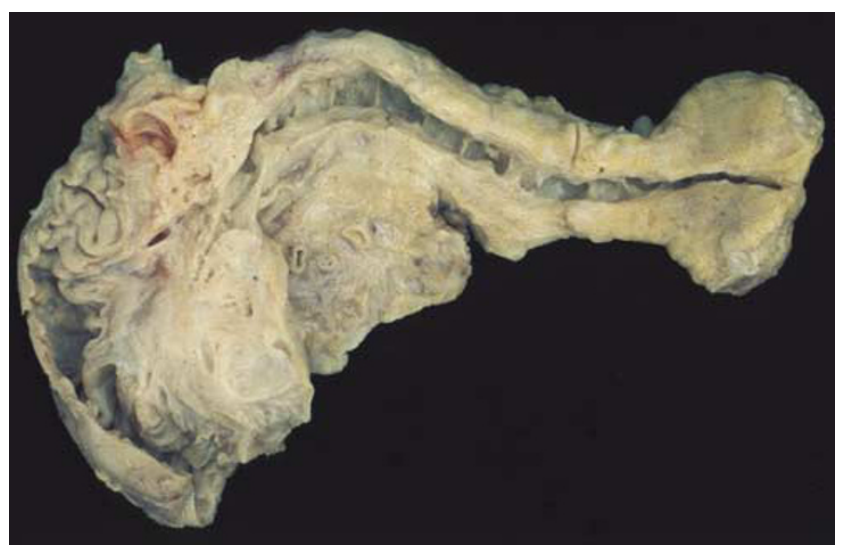

Figure 23 Obstructive chronic pancreatitis: pancreas specimen showing massive dilatation of the pancreatic duct due to an obstructing ductal adenocarcinoma in the head of the gland.

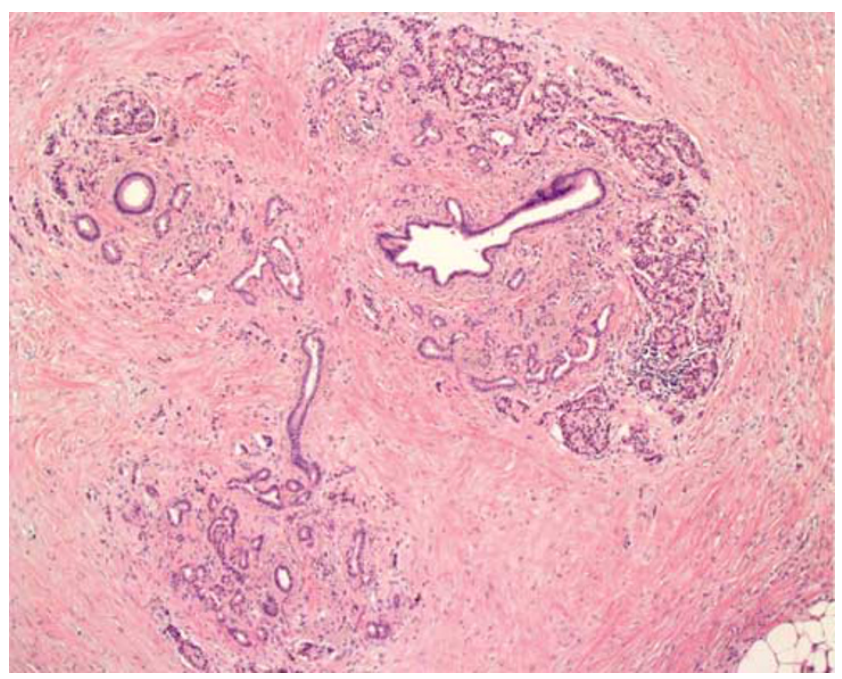

Figure 24 Obstructive chronic pancreatitis, advanced stage: dilated lobular ducts surrounded by remnants of acinar tissue embedded in fibrosis.

elderly persons. Whereas the first condition causes duct obstruction due to clogging with viscous mucin, the second condition leads to narrowing of the duct lumen by papillary hyperplasia of the duct epithelium. In cystic fibrosis, complete or almost complete (inter- and intralobular) fibrosis develops slowly after birth, ${ }^{129}$ which, after many years, is replaced by fatty tissue, ${ }^{130}$ a process that is not understood so far, but is of great interest for the resolution of fibrosis. In cystic fibrosis that is not caused by the common D F508 mutation but results from other mutations such as $\mathrm{R} 117 \mathrm{H}$ mutation, acute pancreatitis may develop. ${ }^{131}$

In elderly persons, the pancreas may contain ducts narrowed by ductal papillary hyperplasia, a lesion that has now been termed pancreatic intraepithelial neoplasia type 1B. ${ }^{132}$ In association with this lesion, there may be patchy lobular fibrosis in the periphery of the pancreas (Figure 25). The 


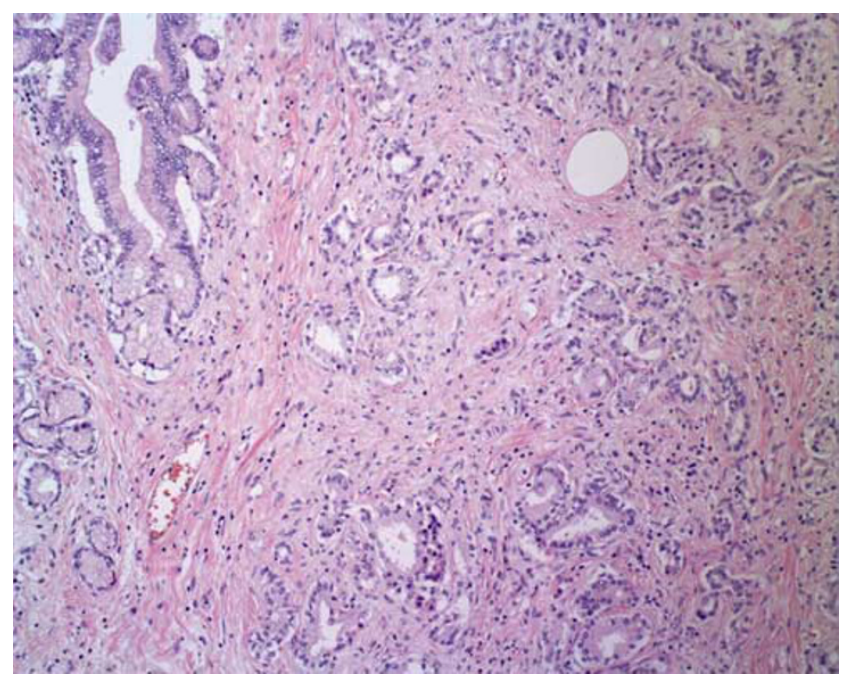

Figure 25 Pancreatic fibrosis not associated with chronic pancreatitis: papillary ductal hyperplasia (pancreatic intraepithelial neoplasia 1B) in the upper left corner associated with an area of intralobular fibrosis.

fibrosis affects the lobes that are drained by ducts showing PanIN-1B lesions. The extent of this lobular fibrosis varies from person to person; the most severe form and the highest incidence (up to 50\%) are found in persons older than 60 years. ${ }^{133}$

\section{Pseudotumors and other tumor-like lesions}

Pseudotumors and other tumor-like lesions are nonneoplastic changes that may mimic pancreatic cancer, in particular ductal adenocarcinoma. Pseudotumors give rise to detectable solid masses and may be either of inflammatory or noninflammatory origin (for further reading see Adsay et $a 1^{134}$ ).

The most important and common inflammatory pseudotumors are those arising in association with autoimmune (lymphoplasmacytic sclerosing) pancreatitis. ${ }^{99}$ These tumors have to be distinguished from malignant fibrous histiocytoma and true inflammatory myofibroblastic tumor. Inflammatory pseudotumors may occasionally be seen in paraduodenal pancreatitis and other rare inflammations such as mycobacterial infection. Among the noninflammatory pseudotumors are ampullary adenomyoma, splenic heterotopia, lipomatous pseudohypertrophy and hamartoma. ${ }^{135,136}$ The tumor-like lesions mainly include cystic changes (see article on cystic neoplasia) and duct changes (see article on ductal adenocarcinoma).

\section{Acknowledgements}

The critical discussion of a number of issues discussed in this manuscript with Drs Volkan Adsay and David Klimstra is acknowledged. I am grateful to Mrs Kay Dege for editing the manuscript.

\section{References}

1 Maisonneuve $\mathrm{P}$, Lowenfels AB, Müllhaupt B, et al. Cigarette smoking accelerates progression of alcoholic chronic pancreatitis. Gut 2005;54:510-514.

2 Ammann RW. The natural history of alcoholic chronic pancreatitis. Intern Med 2001;40:368-375.

3 Etemad B, Whitcomb DC. Chronic pancreatitis: diagnosis, classification, and new genetic developments. Gastroenterology 2001;120:682-707.

4 Lowenfels AB, Maisonneuve P. Epidemiology of chronic pancreatitis and the risk of cancer. In: Büchler MW, Friess H, Uhl W, Malfertheiner P (eds). Chronic Pancreatitis. Novel Concepts in Biology and Therapy. Blackwell Science: Oxford, 2002, pp 29-36.

5 Howes N, Lerch MM, Greenhalf W, et al. Clinical and genetic characteristics of hereditary pancreatitis in Europe. Clin Gastroenterol Hepatol 2004;2:252-261.

6 Ectors N, Maillet B, Aerts R, et al. Non-alcoholic duct destructive chronic pancreatitis. Gut 1997;41: 263-268.

7 Kawaguchi K, Koike M, Tsuruta K, et al. Lymphoplasmacytic sclerosing pancreatitis with cholangitis: variant of primary sclerosing cholangitis extensively involving pancreas. Hum Pathol 1991;22:387-395.

8 Klöppel G, Lüttges J, Löhr M, et al. Autoimmune pancreatitis: pathological, clinical, and immunological features. Pancreas 2003;27:14-19.

9 Notohara K, Burgart LJ, Yadav D, et al. Idiopathic chronic pancreatitis with periductal lymphoplasmacytic infiltration: clinicopathologic features of 35 cases. Am J Surg Pathol 2003;27:1119-1127.

10 Weber SM, Cubukcu-Dimopulo O, Palesty JA, et al. Lymphoplasmacytic sclerosing pancreatitis: inflammatory mimic of pancreatic carcinoma. J Gastrointest Surg 2003;7:129-139.

11 Zamboni G, Lüttges J, Capelli P, et al. Histopathological features of diagnostic and clinical relevance in autoimmune pancreatitis: a study on 53 resection specimens and 9 biopsy specimens. Virchows Arch 2004;445:552-563.

12 Stolte M, Weiss W, Volkholz H, et al. A special form of segmental pancreatitis: 'groove pancreatitis'. Hepatogastroenterology 1982;29:198-208.

13 Becker V, Mischke U. Groove pancreatitis. Int J Pancreatol 1991;10:173-182.

14 Potet F, Duclert N. Cystic dystrophy on aberrant pancreas of the duodenal wall [Article in French]. Arch Fr Mal App Dig 1970;59:223-238.

15 Klöppel G, Detlefsen S, Feyerabend B. Fibrosis of the pancreas: the initial tissue damage and the resulting pattern. Virchows Arch 2004;445:1-8.

16 Ammann RW, Heitz PU, Klöppel G. Course of alcoholic chronic pancreatitis: a prospective clinicomorphological long-term study. Gastroenterology 1996;111:224-231.

17 Klöppel G, Maillet B. The morphological basis for the evolution of acute pancreatitis into chronic pancreatitis. Virchows Arch [A] Pathol Anat 1992;420:1-4.

18 Chari ST, Singer MV. Classification of pancreatitis: problems and prospects. In: Malfertheiner $\mathrm{P}$, Domínguez-Muñoz JE, Schulz HU, Lippert H (eds). 
Diagnostic Procedures in Pancreatic Disease. Springer: Berlin, Heidelberg, 1997, pp 3-10.

19 Layer P, Melle U. Chronic pancreatitis: definition and classification for clinical practice. In: DomínguezMuñoz JE (ed). Clinical Pancreatology for Practising Gastroenterologists and Surgeons. Blackwell: Malden, MA, 2005, pp 180-186.

20 Lowenfels AB, Maisonneuve P, Cavallini G, et al, The International Pancreatitis Study Group. Pancreatitis and the risk of pancreatic cancer. N Engl J Med 1993;328:1433-1437.

21 Klöppel G, Maillet B. Pseudocysts in chronic pancreatitis: a morphological analysis of 57 resection specimens and 9 autopsy pancreata. Pancreas 1991; 6:266-274.

22 Bradley III EL. Pseudocysts in chronic pancreatitis: development and clinical implications. In: Beger HG, Büchler M, Ditschuneit $\mathrm{H}$, Malfertheiner $\mathrm{P}$ (eds). Chronic Pancreatitis. Springer: Berlin, Heidelberg, 1990, pp 260-268.

23 Klöppel G. Pseudocysts and other non-neoplastic cysts of the pancreas. Semin Diagn Pathol 2000; 17:7-15.

24 Klöppel G, Maillet B. Pathology of acute and chronic pancreatitis. Pancreas 1993;8:659-670.

25 Uys CJ, Bank S, Marks IN. The pathology of chronic pancreatitis in Cape Town. Digestion 1973;9:454-468.

26 Ammann RW, Muench R, Otto R, et al. Evolution and regression of pancreatic calcification in chronic pancreatitis. A prospective long-term study of 107 patients. Gastroenterology 1988;95:1018-1028.

27 Howard JM, Nedwich A. Correlation of the histologic observations and operative findings in patients with chronic pancreatitis. Surg Gynecol Obstet 1971; 132:387-395.

28 Detlefsen S, Sipos B, Feyerabend B, et al. Fibrogenesis in alcoholic chronic pancreatitis: the role of tissue necrosis, macrophages, myofibroblasts and cytokines. Mod Pathol 2006;19:1019-1026.

29 Gullo L, Costa PL, Labò G. Chronic pancreatitis in Italy. Aetiological, clinical and histological observations based on 253 cases. Rend Gastroenterol 1977;9:97-104.

30 Bockman DE, Boydston WR, Anderson MC. Origin of tubular complexes in human chronic pancreatitis. Am J Surg 1982;144:243-249.

31 Bockman DE, Büchler M, Malfertheiner $\mathrm{P}$, et al. Analysis of nerves in chronic pancreatitis. Gastroenterology 1988;94:1459-1469.

32 Klöppel G, Bommer G, Commandeur G, et al. The endocrine pancreas in chronic pancreatitis. Immunocytochemical and ultrastructural studies. Virchows Arch [A] Pathol Anat 1978;377:157-174.

33 Bedossa P, Bacci J, Lemaigre G, et al. Lymphocyte subsets and HLA-DR expression in normal pancreas and chronic pancreatitis. Pancreas 1990;5:415-420.

34 Jalleh RP, Gilbertson JA, Williamson RC, et al. Expression of major histocompatibility antigens in human chronic pancreatitis. Gut 1993;34:1452-1457.

35 Korc M, Friess H, Yamanaka Y, et al. Chronic pancreatitis is associated with increased concentrations of epidermal growth factor receptor, transforming growth factor $\alpha$, and phospholipase C gamma. Gut 1994;35:1468-1473.

36 Friess H, Yamanaka Y, Büchler M, et al. A subgroup of patients with chronic pancreatitis overexpress the C-erb B-2 protooncogene. Ann Surg 1994;220:183-192.
37 van Laethem JL, Devière J, Resibois A, et al. Localizing of transforming growth factor $\beta 1$ and its latent binding protein in human chronic pancreatitis. Gastroenterology 1995;108:1873-1881.

38 Friess H, Yamanaka Y, Büchler M, et al. Increased expression of acidic and basic fibroblast growth factors in chronic pancreatitis. Am J Pathol 1994;144:117-128.

39 Ebert M, Kasper HU, Hernberg S, et al. Overexpression of platelet-derived growth factor (PDGF) B chain and type $\beta$ PDGF receptor in human chronic pancreatitis. Dig Dis Sci 1998;43:567-574.

40 Luttenberger T, Schmid-Kotsas A, Menke A, et al. Platelet-derived growth factors stimulate proliferation and extracellular matrix synthesis of pancreatic stellate cells: implication in pathogenesis of pancreas fibrosis. Lab Invest 2000;80:47-55.

41 Apte MV, Haber PS, Darby SJ, et al. Pancreatic stellate cells are activated by proinflammatory cytokines: implications for pancreatic fibrogenesis. Gut 1999; 44:534-541.

42 Bachem MG, Schneider E, Gross H, et al. Identification, culture, and characterization of pancreatic stellate cells in rats and humans. Gastroenterology 1998;115:421-432.

43 Barth PJ, Ebrahimsade S, Hellinger A, et al. CD34+ fibrocytes in neoplastic and inflammatory pancreatic lesions. Virchows Arch 2002;440:128-133.

44 Klöppel G, Dreyer T, Willemer S, et al. Human acute pancreatitis: its pathogenesis in the light of immunocytochemical and ultrastructural findings in acinar cells. Virchows Arch [A] Pathol Anat 1986;409: 791-803

45 Lechene de la Porte $\mathrm{P}$, de Caro $\mathrm{A}$, Lafont $\mathrm{H}$, et al. Immunocytochemical localization of pancreatic stone protein in the human digestive tract. Pancreas 1986;1:301-308.

46 Büchler $\mathrm{M}$, Weihe $\mathrm{D}$, Friess $\mathrm{H}$, et al. Changes in peptidergic innervation in chronic pancreatitis. Pancreas 1992;7:183-192.

47 Kakugawa Y, Giaid A, Yanagisawa M, et al. Expression of endothelin-1 in pancreatic tissue of patients with chronic pancreatitis. J Pathol 1996;178:78-83.

48 Yadegar J, Williams RA, Passaro Jr E, et al. Common duct stricture from chronic pancreatitis. Arch Surg 1980;115:582-586.

49 Kozarek RA. Pancreatic stents can induce ductal changes consistent with chronic pancreatitis. Gastrointest Endosc 1990;36:93-95.

50 Sherman S, Alvarez C, Robert M, et al. Polyethylene pancreatic duct stent-induced changes in the normal dog pancreas. Gastrointest Endosc 1993;39:658-664.

51 Pour PM. Is there a link between chronic pancreatitis and pancreatic cancer? In: Beger HG, Büchler M, Ditschuneit H, Malfertheiner P (eds). Chronic Pancreatitis. Springer: Berlin, Heidelberg, 1990, pp 106112.

52 Sgambati SA, Lawton GP, Modlin IM. Chronic pancreatitis: a precursor to pancreatic carcinoma? Dig Surg 1994;11:275-285.

53 Löhr M, Klöppel G, Maisonneuve P, et al. Frequency of K-ras mutations in pancreatic intraductal neoplasias associated with pancreatic ductal adenocarcinoma and chronic pancreatitis: a meta-analysis. Neoplasia 2005;7:17-23.

54 Worning $H$. Incidence and prevalence of chronic pancreatitis. In: Beger HG, Büchler M, Ditschuneit H, 
Malfertheiner P (eds). Chronic Pancreatitis. Springer: Berlin, Heidelberg, 1990, pp 8-14.

55 Mössner J. Epidemiology of chronic pancreatitis. In: Beger HG, Büchler M, Malfertheiner P (eds). Standards in Pancreatic Surgery. Springer: Berlin, 1993, pp 263-271.

56 Lankisch PG, Banks PA. Pancreatitis. Springer: Berlin, 1998.

57 Dreiling DA, Koller M. The natural history of alcoholic pancreatitis: update 1985. Mt Sinai J Med 1985;52:340-342.

58 Papachristou GI, Whitcomb DC. Etiopathogenesis of chronic pancreatitis: a genetic disease with some precipitating factors? In: Domínguez-Muñoz JE (ed). Clinical Pancreatology for Practising Gastroenterologists and Surgeons. Blackwell: Malden, MA, 2005, pp 192-200.

59 Suda K, Takase M, Takei K, et al. Histopathologic study of coexistent pathologic states in pancreatic fibrosis in patients with chronic alcohol abuse: two distinct pathologic fibrosis entities with different mechanisms. Pancreas 1996;12:369-372.

60 Sarles H, Payan H, Tasso F, et al. Chronic pancreatitis, relapsing pancreatitis, calcification of the pancreas In: Bockus HL (ed). Gastroenterology, 2nd edn. WB Saunders: Philadelphia, 1976, pp 1040-1051.

61 Multigner I, Sarles H, Lombardo D, et al. Pancreatic stone protein II: implication in stone formation during the course of chronic calcifying pancreatitis. Gastroenterology 1985;89:387-391.

62 Sarles H, Bernard JP, Gullo L. Pathogenesis of chronic pancreatitis. Gut 1990;31:629-632.

63 Sarles H, Muratore R, Sarles JC, et al. Aetiology and pathology of chronic pancreatitis. In: Sarles H (ed). Pancreatitis (Bibliotheca Gastroenterologica No. 7). Karger: Basel, 1965, pp 75-120.

64 Schmiegel W, Burchert M, Kalthoff H, et al. Immunochemical characterization and quantitative distribution of pancreatic stone protein in sera and pancreatic secretions in pancreatic disorders. Gastroenterology 1990;99:1421-1430.

65 Schmiegel W. PSP, PTP, or REG protein? The role of pancreatic stone protein. In: Beger HG, Büchler M, Malfertheiner P (eds). Standards in Pancreatic Surgery. Springer: Berlin, 1993, pp 281-289.

66 Hayakawa T, Naruse S, Kitagawa M, et al. Pancreatic stone protein and lactoferrin in human pancreatic juice in chronic pancreatitis. Pancreas 1995;10: 137-142.

67 Seligson U, Cho JW, Ihse I, et al. Clinical course and autopsy findings in acute and chronic pancreatitis. Acta Chir Scand 1982;148:269-274.

68 Renner IG, Savage WT, Pantoja JL, et al. Death due to acute pancreatitis. A retrospective analysis of 405 autopsy cases. Dig Dis Sci 1985;30:1005-1018.

69 Klöppel G, Willemer S, Stamm B, et al. Pancreatic lesions and hormonal profile of pancreatic tumors in multiple endocrine neoplasia type I. An immunocytochemical study of nine patients. Cancer 1986; 57:1824-1832.

70 Marks IN, Bornman PC. Acute alcoholic pancreatitis: a South African viewpoint. In: Bradley EL3 (ed). Acute Pancreatitis: Diagnosis and Therapy. Raven: New York, 1994, pp 271-277.

71 Comfort MW, Gambill EE, Baggenstoss AH. Chronic relapsing pancreatitis. A study of twenty-nine cases without associated disease of the biliary or gastro- intestinal tract. Gastroenterology 1946;6:239-285, 376-408.

72 Ammann RW, Muellhaupt B. Progression of alcoholic acute to chronic pancreatitis. Gut 1994;35:552-556.

73 Klöppel G. Chronic pancreatitis of alcoholic and nonalcoholic origin. Semin Diagn Pathol 2004; 21:227-236.

74 Tabata T, Fujimoro T, Maeda S, et al. The role of ras mutation in pancreatic cancer, precancerous lesions, and chronic pancreatitis. Int J Pancreatol 1993; 14:237-244.

75 DiMagno EP, Layer P, Clain JE. Chronic pancreatitis. In: Go VLW, Di Magno EP, Gardner JD, Lebenthal E, Reber HA, Scheele GA (eds). The Pancreas: Biology, Pathobiology, and Disease, 2nd edn. Raven Press: New York, 1993, pp 665-706.

76 Bank S. Chronic pancreatitis: clinical features and medical management. Am J Gastroenterol 1986; 81:153-167.

77 Bordalo O, Bapista A, Dreiling D, et al. Early pathomorphological pancreatic changes in chronic alcoholism. In: Gyr KE, Singer MV, Sarles H (eds). Pancreatitis-Concepts and Classification. Elsevier: Amsterdam, (Exerpta Medica, International Congress Series No. 642) 1984.

78 Noronha M, Bordalo O, Dreiling DA. Alcohol and the pancreas. II. Pancreatic morphology of advanced alcoholic pancreatitis. Am J Gastroenterol 1981; 76:120-124.

79 Braganza JM. Pancreatic disease: a casualty of hepatic 'detoxification'? Lancet 1983;ii:1000-1003.

80 Whitcomb DC, Gorry MC, Preston RA, et al. Hereditary pancreatitis is caused by a mutation in the cationic trypsinogen gene. Nat Genet 1996;14: 141-145.

81 Witt H, Becker M. Genetics of chronic pancreatitis. J Pediatr Gastroenterol Nutr 2002;34:125-136.

82 Witt H, Luck W, Hennies HC, et al. Mutations in the gene encoding the serine protease inhibitor, Kazal type 1 are associated with chronic pancreatitis. Nat Genet 2000;25:213-216.

83 Konzen KM, Perrault J, Moir C, et al. Long-term follow-up of young patients with chronic hereditary or idiopathic pancreatitis. Mayo Clin Proc 1993; 68:449-453.

84 Ball WP, Baggenstoss AH, Bargen JA. Pancreatic lesions associated with chronic ulcerative colitis. Arch Pathol 1950;50:347-358.

85 Sarles H, Sarles JC, Muratore R, et al. Chronic inflammatory sclerosis of the pancreas-an autoimmune pancreatic disease? Am J Dig Dis 1961;6: 688-698.

86 Yoshida K, Toki F, Takeuchi T, et al. Chronic pancreatitis caused by an autoimmune abnormality. Proposal of the concept of autoimmune pancreatitis. Dig Dis Sci 1995;40:1561-1568.

87 Sood S, Fossard DP, Shorrock K. Chronic sclerosing pancreatitis in Sjögren's syndrome: a case report. Pancreas 1995;10:419-421.

88 Abraham SC, Wilentz RE, Yeo CJ, et al. Pancreaticoduodenectomy (Whipple resections) in patients without malignancy. Are they all 'chronic pancreatitis'? Am J Surg Pathol 2003;27:110-120.

89 Ito T, Nakano I, Koyanagi S, et al. Autoimmune pancreatitis as a new clinical entity. Three cases of autoimmune pancreatitis with effective steroid therapy. Dig Dis Sci 1997;42:1458-1468. 
90 Uchida K, Okazaki K, Konishi Y, et al. Clinical analysis of autoimmune-related pancreatitis. Am J Gastroenterol 2000;95:2788-2794.

91 Hamano H, Kawa S, Horiuchi A, et al. High serum IgG4 concentrations in patients with sclerosing pancreatitis. N Engl J Med 2001;344:732-738.

92 Hirano K, Komatsu Y, Yamamoto N, et al. Pancreatic mass lesions associated with raised concentration of IgG4. Am J Gastroenterol 2004;99:2038-2040.

93 Scully KA, Li SC, Hebert JC, et al. The characteristic appearance of non-alcoholic duct destructive chronic pancreatitis. A report of 2 cases. Arch Pathol Lab Med 2000;124:1535-1538.

94 Youssef N, Petitjean B, Bonte H, et al. Non-alcoholic duct destructive chronic pancreatitis: a histological, immunohistochemical and in-situ apoptosis study of 18 cases. Histopathology 2004;44:453-461.

95 Sahin P, Pozsár J, Simon K, et al. Autoimmune pancreatitis associated with immune-mediated inflammation of the papilla of Vater. Report on two cases. Pancreas 2004;29:162-166.

96 Hamano H, Kawa S, Ochi Y, et al. Recurrent attacks of autoimmune pancreatitis result in pancreatic stone formation. Pancreatology 2004;4:297.

97 Abraham SC, Leach S, Yeo CJ, et al. Eosinophilic pancreatitis and increased eosinophils in the pancreas. Am J Surg Pathol 2003;27:334-342.

98 Esposito I, Bergmann F, Penzel R, et al. Oligoclonal T-cell populations in an inflamatory pseudotumor of the pancreas possibly related to autoimmune pancreatitis: an immunohistochemical and molecular analysis. Virchows Arch 2004;444:119-126.

99 Mizukami H, Yajima N, Wada R, et al. Pancreatic malignant fibrous histiocytoma, inflammatory myofibroblastic tumor, and inflammatory pseudotumor related to autoimmune pancreatitis: characterization and differential diagnosis. Virchows Arch 2006; 448:552-560.

100 Abraham SC, Cruz-Correa M, Argani P, et al. Lymphoplasmacytic chronic cholecystitis and biliary tract disease in patients with lymphoplasmacytic sclerosing pancreatitis. Am J Surg Pathol 2003; 27:441-451.

101 Deshpande V, Mino-Kenudson M, Brugge WR, et al. Endoscopic ultrasound guided fine needle aspiration biopsy of autoimune pancreatitis. Diagnostic criteria and pitfalls. Am J Surg Pathol 2005;29:1464-1471.

102 Wreesmann V, van Eijck CHJ, Naus DCWH, et al. Inflammatory pseudotumour (inflammatory myofibroblastic tumour) of the pancreas: a report of six cases associated with obliterative phlebitis. Histopathology 2001;38:105-110.

103 Uchida K, Okazaki K, Asada M, et al. Case of chronic pancreatitis involving an autoimmune mechanism that extended to retroperitoneal fibrosis. Pancreas 2003;26:92-94.

104 Chutaputti A, Burrell MI, Boyer JL. Pseudotumor of the pancreas associated with retroperitoneal fibrosis: a dramatic response to corticosteroid therapy. Am J Gastroenterol 1995;90:1155-1158.

105 Renner IG, Ponto GC, Savage III WT, et al. Idiopathic retroperitoneal fibrosis producing common bile duct and pancreatic duct obstruction. Gastroenterology 1980;79:348-351.

106 Nonomura A, Minato H, Shimizu K, et al. Hepatic hilar inflammatory pseudotumor mimicking cholangiocarcinoma with cholangitis and phlebitis-a variant of primary sclerosing cholangitis? Pathol Res Pract 1997;193:519-525.

107 Okazaki K, Uchida K, Ohana M, et al. Autoimmunerelated pancreatitis is associated with autoantibodies and a Th1/Th2-type cellular immune response. Gastroenterology 2000;118:573-581.

108 Ajjan RA, McIntosh RS, Waterman EA, et al. Analysis of the T-cell receptor Valpha repertoire and cytokine gene expression in Sjögren's syndrome. Br J Rheumatol 1998;37:179-185.

109 Dienes HP, Lohse AW, Gerken G, et al. Bile duct epithelia as target cells in primary biliary cirrhosis and primary sclerosing cholangitis. Virchows Arch 1997;431:119-124.

110 Kawa S, Ota M, Yoshizawa K, et al. HLA DRB10405DQB10401 haplotype is associated with autoimmune pancreatitis in the Japanese population. Gastroenterology 2002;122:1264-1269.

111 Kamisawa T, Funata N, Hayashi Y, et al. Close relationship between autoimmune pancreatitis and multifocal fibrosclerosis. Gut 2003;52:683-687.

112 Kojima M, Sipos B, Klapper W, et al. Autoimmune pancreatitis: frequency, IgG4 expression and clonality of T and B cells. Am J Surg Pathol 2006 (in press).

113 Erkelens GW, Vleggaar FP, Lesterhuis W, et al. Sclerosing pancreato-cholangitis responsive to steroid therapy. Lancet 1999;354:43-44.

114 Okazaki K. Autoimmune-related pancreatitis. Curr Treat Opt Gastroenterol 2001;4:369-375.

115 Saito T, Tanaka S, Yoshida $\mathrm{H}$, et al. A case of autoimmune pancreatitis responding to steroid therapy. evidence of histologic recovery. Pancreatology 2002;2:550-556.

116 Horiuchi A, Kawa S, Hamano H, et al. ERCP features in 27 patients with autoimmune pancreatitis. Gastrointest Endosc 2002;55:494-499.

117 Kamisawa T, Egawa N, Nakajima H, et al. Morphological changes after steroid therapy in autoimmune pancreatitis. Scand J Gastroenterol 2004;11:11541158.

118 Lack EE. Pancreatitis. In: Lack EE (ed). Pathology of the Pancreas, Gallbladder, Extrahepatic Biliary Tract, and Ampullary Region. Oxford University Press: Oxford, 2003, pp 81-117.

119 Rossi L, Pfützer RH, Parvin S, et al. SPINK1/PSTI mutations are associated with tropical pancreatitis in Bangladesh. A preliminary report. Pancreatology 2001;1:242-245.

120 Pitchumoni CS, Varughese M. Tropical calculous pancreatitis. In: Howard J, Idezuki Y, Ihse I, Prinz R (eds). Surgical Diseases of the Pancreas, 3rd edn. Williams \& Wilkins: Baltimore, 1998, pp 411-416.

121 Ammann RW, Buehler H, Muench R, et al. Differences in the natural history of idiopathic (nonalcoholic) and alcoholic chronic pancreatitis. A comparative long-term study of 287 patients. Pancreas 1987:2:368-377.

122 Layer P, Yamamoto H, Kalthoff L, et al. The different courses of early- and late-onset idiopathic and alcoholic chronic pancreatitis. Gastroenterology 1994;107:1481-1487.

123 Fléjou JF, Potet F, Molas G, et al. Cystic dystrophy of the gastric and duodenal wall developing in heterotopic pancreas: an unrecognized entity. Gut 1993;34:343-347. 
124 Solcia E, Capella C, Klöppel G. Tumors of the Pancreas. AFIP Atlas of Tumor Pathology Third Series, Fascicle 20 Armed Forces Institute of Pathology: Washington, DC, 1997.

125 McFaul CD, Vitone LJ, Campbell F, et al. Pancreatic hamartoma. Pancreatology 2004;4:533-537.

126 Adsay NV, Zamboni G. Paraduodenal pancreatitis: a clinico-pathologically distinct entity unifying 'cystic dystrophy of heterotopic pancreas,' 'para-duodenal wall cyst,' and 'groove pancreatitis'. Semin Diagn Pathol 2004;21:247-254.

127 Hultquist GT, Jönsson LE. Ligation of the pancreatic duct in rats. Acta Soc Med Upsal 1965;70:82-88.

128 Isaksson G, Ihse I, Lundquist I. Influence of pancreatic duct ligation on endocrine and exocrine rat pancreas. Acta Physiol Scand 1983;117:281-286.

129 Seifert G. Cystic fibrosis and haemochromatosis. In: Klöppel G, Heitz PU (eds). Pancreatic Pathology Chapter 4. Churchill Livingstone: Edinburgh, 1984, pp 32-43.

130 Lack EE. Cystic fibrosis and selected disorders with pancreatic insufficiency. In: Lack EE (ed). Pathology of the Pancreas, Gallbladder, Extrahepatic Biliary
Tract, and Ampullary Region. Oxford University Press: Oxford, 2003, pp 63-80.

131 Milla PJ. Cystic fibrosis: present and future. Digestion 1998;59:579-588.

132 Hruban RH, Adsay NV, Albores-Saavedra J, et al. Pancreatic intraepithelial neoplasia. A new nomenclature and classification system for pancreatic duct lesions. Am J Surg Pathol 2001;25:579-586.

133 Detlefsen S, Sipos B, Feyerabend B, et al. Pancreatic fibrosis associated with age and ductal papillary hyperplasia. Virchows Arch 2005;447:800-805.

134 Adsay NV, Basturk O, Klimstra DS, et al. Pancreatic pseudotumors: non-neoplastic solid lesions of the pancreas that clinically mimic pancreas cancer. Semin Diagn Pathol 2004;21:260-267.

135 Pauser U, da Silva MTS, Placke J, et al. Cellular hamartoma resembling gastrointestinal stromal tumor: a solid tumor of the pancreas expressing c-kit (CD117). Mod Pathol 2005;18:1211-1216.

136 Pauser U, Kosmahl M, Kruslin B, et al. Pancreatic solid and cystic hamartoma in adults: characterization of a new tumorous lesion. Am J Surg Pathol 2005;29:797-800. 